\title{
Monoaminergic Modulation of Motor Cortex Function
}

\author{
Clément Vitrac ${ }^{1,2 \dagger}$ and Marianne Benoit-Marand ${ }^{1,2 *}$ \\ 'Laboratoire de Neurosciences Expérimentales et Cliniques, INSERM U1084, Poitiers, France, ${ }^{2}$ Laboratoire de \\ Neurosciences Expérimentales et Cliniques, Université de Poitiers, Poitiers, France
}

Elaboration of appropriate responses to behavioral situations rests on the ability of selecting appropriate motor outcomes in accordance to specific environmental inputs. To this end, the primary motor cortex (M1) is a key structure for the control of voluntary movements and motor skills learning. Subcortical loops regulate the activity of the motor cortex and thus contribute to the selection of appropriate motor plans. Monoamines are key mediators of arousal, attention and motivation. Their firing pattern enables a direct encoding of different states thus promoting or repressing the selection of actions adapted to the behavioral context. Monoaminergic modulation of motor systems has been extensively studied in subcortical circuits. Despite evidence of converging projections of multiple neurotransmitters systems in the motor cortex pointing to a direct modulation of local circuits, their contribution to the execution and learning of motor

OPEN ACCESS

Edited by:

Srikanth Ramaswamy, École Polytechnique Fédérale de Lausanne, Switzerland

Reviewed by: Rune W. Berg, University of Copenhagen, Denmark Kuan Hong Wang, National Institute of Mental Health $(\mathrm{NIH})$, United States

*Correspondence: Marianne Benoit-Marand marianne.benoit.marand@ univ-poitiers.fr

${ }^{\dagger}$ Present address: Clément Vitrac,

Vascular Neurology and Rehabilitation, Department of Neurology, University of Zürich,

Zürich, Switzerland

Received: 30 July 2017 Accepted: 19 September 2017 Published: 09 October 2017

Citation:

Vitrac $C$ and Benoit-Marand M (2017) Monoaminergic Modulation of Motor Cortex Function. Front. Neural Circuits 11:72. doi: 10.3389/fncir.2017.00072 skills is still poorly understood. Monoaminergic dysregulation leads to impaired plasticity and motor function in several neurological and psychiatric conditions, thus it is critical to better understand how monoamines modulate neural activity in the motor cortex. This review aims to provide an update of our current understanding on the monoaminergic modulation of the motor cortex with an emphasis on motor skill learning and execution under physiological conditions.

Keywords: motor cortex, monoamines, dopamine, norepinephrine, serotonin, histamine

\section{INTRODUCTION}

Primary motor cortex (M1) plays a key role in volitional motor control and motor skills learning. M1 neurons are organized in six layers of different populations, about $80 \%$ are excitatory glutamatergic neurons and 20\% inhibitory $\gamma$-amino butyric acidergic (GABA) interneurons (INs; Lev and White, 1997). These neurons are clustered in functional groups and act in a highly specific interconnected local network which processes and transfers the afferent information to cortical and subcortical structures such as the spinal cord and striatum (Zhang and Deschênes, 1997; Lei et al., 2004; Weiler et al., 2008; Anderson et al., 2010; Kiritani et al., 2012; Hira et al., 2013; Oswald et al., 2013; Potjans and Diesmann, 2014; Figure 1). Indeed, M1 receive multiple inputs from other cortical and subcortical structures (Zhang and Deschênes, 1997, 1998; Molyneaux et al., 2007; Kuramoto et al., 2009). Thalamo-cortical projections reach a small band of pyramidal neurons at the layer III/IV border-which shares characteristics with layer IV pyramidal neurons from sensory cortices (Shepherd, 2009; Yamawaki et al., 2014; Barbas and García-Cabezas, 2015). For the sake of simplicity, we will refer to this thin layer of neurons as layer IV. Layer IV neurons project to layer II/III neurons (Potjans and Diesmann, 2014) which contact preferentially the corticostriatal neurons in layer $\mathrm{V}$ and to a lesser extent the corticospinal neurons (Cho et al., 2004a,b; Anderson et al., 2010). Corticostriatal neurons send projections to both striatal and to corticospinal neurons (Kiritani et al., 2012). In parallel to this excitatory network, an inhibitory ascendant circuit is 


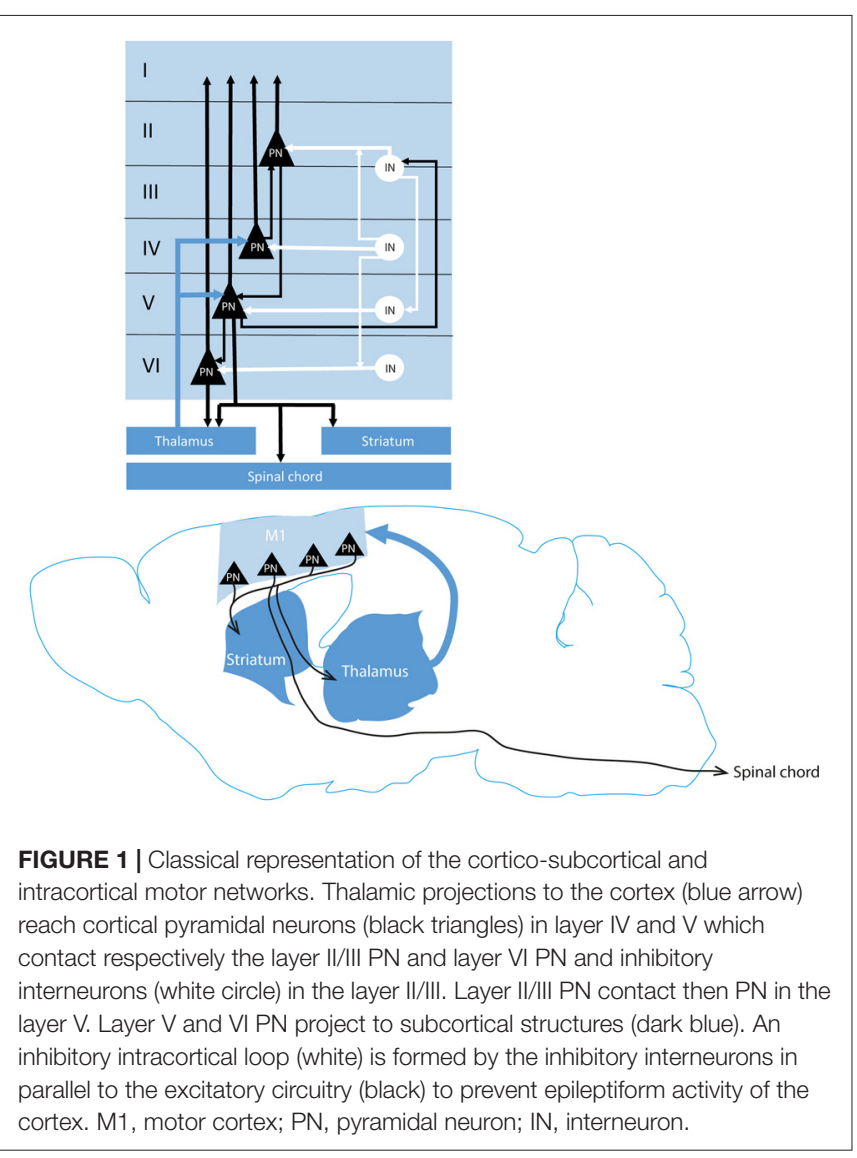

recruited to limit the duration of the intracortical activation (Weiler et al., 2008). The somatotopic representation of the body parts is a hallmark of M1 functional organization (Neafsey et al., 1986; Tennant et al., 2011). Experience and training change both the motor maps representations and the excitability of M1 (Nudo et al., 1996; Kleim et al., 1998; Molina-Luna et al., 2008). Synaptic transmission in M1 layer II/III is enhanced in rats after learning a skilled reaching task and synchrony between single neuron activity is increased along training in mice M1 (Rioult-Pedotti et al., 1998, 2000; Peters et al., 2014).

Appropriate behavioral responses to the environment require the ability of networks to integrate environmental clues in order to elaborate appropriate motor responses. The reliability of signal transmission by a neural network is supported by the ability of individual neurons within the network to detect and integrate the signal among the noise. This can be measured by the ratio of signal power to noise power and is referred as signal to noise ratio. Cortical information processing is believed to be sustained by a local excitatory circuit involving monosynaptic connections between PN sustaining persistent activity and an inhibitory network due to non-pyramidal connections onto PN that ensure temporal integration (Durstewitz et al., 2000; Constantinidis and Goldman-Rakic, 2002). This local excitatory/inhibitory network support the increased signal to noise ratio in cortical neurons and is mediated by neuromodulators (ServanSchreiber et al., 1990; Durstewitz et al., 2000; Kroener et al., 2009).
Neuromodulatory transmitters in the neocortex include monoamines and acetylcholine, this systems share a number of common features and interact locally to shape cortical activity (Gu, 2002). Monoaminergic neurons activity depends on external clues, their role in shaping cortical and subcortical networks activity suggest that they are key players in the fine tuning of adapted motor responses to a given behavioral context.

This review aims to provide an overview of our current knowledge on the role of monoamines on motor cortex function and to integrate all these pieces of information together to propose a hypothesis on cortical monoamine interplay in the regulation of motor response to a given environmental context.

\section{DOPAMINE MODULATION OF MOTOR CORTEX FUNCTION}

Cortical dopamine (DA) is mainly provided by neurons projecting from the ventral tegmental area (VTA) to the cortex. The mesocortical pathway from the VTA to the prefrontal cortex (PFC) has been well studied, especially in the context of high cognitive processes. The role of DA in executive function and more specifically in motor execution is usually addressed through the study of the basal ganglia modulation by nigrostriatal dopaminergic pathway from the substantia nigra pars compacta to the striatum. However, increasing evidence points to a direct modulation of motor control through a dopaminergic innervation of the motor cortex. DA is synthetized by two enzymatic steps, first the hydroxylation of tyrosine in dihydroxyphenylalanine (DOPA), then the decarboxylation of DOPA by the aromatic amino-acid decarboxylase (AADC) results in DA (Pour revue: Meiser et al., 2013). DA is internalized in vesicles by the vesicular monoamine transporter VMAT2.

Dopaminergic neurons are characterized by their bimodal electrophysiological firing frequencies. As shown in rodents and primates, they exhibit in vivo two firing patterns, a tonic firing consisting in an irregular activity at $4 \mathrm{~Hz}$ and in response to an appetitive or salient stimulus they fire a burst of 2-6 action potentials (AP) at a frequency of $15 \mathrm{~Hz}$ (Grace and Bunney, 1984a,b; Freeman and Bunney, 1987; Kosobud et al., 1994; Mirenowicz and Schultz, 1996; Floresco et al., 2003). Dopaminergic neurons can also code for aversive stimuli by a pause in their tonic firing rate (Schultz, 1998; Eshel et al., 2016). Although some studies suggest that aversion signals modulate DA differentially across different areas, in rodents the three different firing frequencies coding for environmental clues result in different extracellular levels of DA in the striatum due to the kinetics of DA elimination by presynaptic reuptake (Chergui et al., 1994; Benoit-Marand et al., 2000; Floresco et al., 2003; Badrinarayan et al., 2012; Ilango et al., 2012). Computational models suggest that the heterogeneity of extracellular DA release among different regions is due to local differences in autoinhibition feedback (Dreyer et al., 2016). Moreover these models show that the different DA firing patterns result in differential DA receptors occupancy (Dreyer et al., 2010). 


\section{Neuroanatomical Evidence}

Early studies have suggested that the motor cortex receives dopaminergic innervation. By using tritiated DA, Descarries et al. (1987) showed the presence of dopaminergic varicosities in layer VI of the entire dorsofrontal cortex in rats, including M1. Later, Gaspar et al. (1991) showed in the human motor cortex the existence of catecholaminergic fibers expressing the tyrosine hydroxylase (TH) but not the dopamine $\beta$ hydroxylase $(\mathrm{DBH})$, specifically expressed by noradrenergic fibers, thus indirectly demonstrating that human motor cortex is innervated by dopaminergic fibers. Raghanti et al. (2008) showed that TH-expressing fibers innervate M1 in macaques and chimpanzees. Nevertheless, even if TH seems weakly colocalized with $\mathrm{DBH}$ in primates' cortex, these results did not directly demonstrate a dopaminergic innervation of M1 (Gaspar et al., 1989). However, in an elegant study, Hosp et al. (2011) showed that VTA dopaminergic cells project to M1 in rats (Figure 2). The density of the dopaminergic cell bodies innervating the motor cortex in rats decreases in a rostro-caudal gradient inside the VTA (Hosp et al., 2015). These anatomical data suggest that the motor cortex could constitute a territory of limbic and motor interaction. Our group described more specifically the organization of M1 dopaminergic innervation in mice by staining the DA transporter (DAT), specifically expressed by the dopaminergic fibers (Ciliax et al., 1995; Vitrac et al., 2014). We demonstrated that the dopaminergic fibers network in M1 deep layers is dense enough to suggest a modulatory role of M1 activity (Figure 2). Moreover, the dopaminergic fibers preferentially target the forelimb representation map of $\mathrm{M} 1$ in rodents supporting the hypothesis that DA innervation from the VTA could modulate M1 neuronal activity (Vitrac et al., 2014; Hosp et al., 2015).

DA tissue levels are detected in the motor cortex. Even though DA concentration in the somatomotor cortex is about 50 times lower than in striatum, the functional implication of DA in cortical regions has been well documented (Godefroy et al., 1991; Awenowicz and Porter, 2002; López-Avila et al., 2004; Schweimer and Hauber, 2006; Hosp et al., 2009; Molina-Luna et al., 2009).

DA acts via five different receptors grouped in two classes, D1 like and D2 like, respectively activating and inhibiting adenylyl cyclase (Jaber et al., 1996). D1-type DA receptors and D2-type DA receptors are expressed in cortical areas of numerous mammalian species, including the motor cortex of rodents (Camps et al., 1990; Mansour et al., 1990; Gaspar et al., 1995). In primates, D1, D2 and D5 mRNAs are found in the motor cortex throughout layers II-V (Huntley et al., 1992). In rodents, D1 receptors are preferentially expressed in layer VI whereas D2 receptors are preferentially expressed in layer $\mathrm{V}$ in all the frontal areas, but there is no anatomical evidence indicating whether DA receptors are expressed by $\mathrm{PN}$, interneurons, or both, in M1 (Gaspar et al., 1995). This point is of great importance to understand how DA modulates neuronal activity in this structure.

\section{Evidence for a Dopaminergic Modulation of Motor Cortex Activity}

Direct evidence of the effect of DA on M1 neuronal activity are scarce and conflicting. To date, direct dopaminergic modulation of M1 activity has been essentially studied by in vivo electrophysiological techniques. Iontophoretic application of high DA concentration in M1 induced a depressing effect on M1 PN activity in anesthetized rats and a decrease of their response to thalamic and callosal afferences in anesthetized cats (Huda et al., 2001; Awenowicz and Porter, 2002). Furthermore, iontophoretic application of D1 as well as D2 receptor antagonists blocks the depressing effects of DA, demonstrating that DA could inhibit M1 PN activity by a synergistic activation of D1 and D2 receptors (Huda et al., 2001; Awenowicz and Porter, 2002). However, a more recent study showed that a local activation of D2 receptor by a quinpirole injection in the vicinity of recorded $\mathrm{PN}$ enhances $\mathrm{PN}$ firing rate, demonstrating that DA has an excitatory role via D2 receptor activation (Vitrac et al., 2014). M1 functional outcome can be studied by the extent of its motor representation map as well as by the stimulation threshold required to evoke a motor response. Indeed, peripheral injection of haloperidol, a D2-like receptor antagonist, slows movements and reduces M1 neuronal activity in behaving rats (Parr-Brownlie and Hyland, 2005). Haloperidol administration also results in a decrease of the distal forelimb representation map of M1 in anesthetized rats (Brown et al., 2009). Intracortical injection of a D2, but not D1, receptor antagonist in anesthetized rats confirms the decrease of the distal forelimb representation map of M1 (Hosp et al., 2009). Moreover, Hosp et al. (2009) also demonstrated an increase of both threshold and latency of intracortical-microstimulation (ICMS)-evoked movement after D2 blockade, suggesting that D2 receptors promote neuronal excitability (Figure 2). Interestingly, patch-clamp experiments on PFC slices of adult mice demonstrated that D2 receptor activation with quinpirole selectively prolongs the depolarization of activated PN expressing the D2 receptors by enhancing L-type calcium currents (Gee et al., 2012), confirming that D2 receptor activation can enhance $\mathrm{PN}$ activity. However, the behavioral outcome of this modulation is still to be unraveled.

Altogether, these results demonstrate that D2 receptors activation could have an excitatory effect on M1 neuronal activity whereas D1 receptors may not be involved in the modulation of M1 activity. To date, there is no evidence in M1 suggesting a direct effect of D2 receptors on corticospinal neurons, a local network effect involving interneurons, or both. However, studies conducted in the PFC show that VTA stimulation increases both PNs and INs firing (Seamans and Yang, 2004; Tseng et al., 2006). As well, the phasic activation of VTA dopaminergic neurons enhances the general excitatory activity as well as gamma oscillations in the secondary motor cortex in mice (Mastwal et al., 2014). Noteworthy, synchronous activation of GABAergic interneurons and PN is responsible for gamma oscillations in cortical structures (Whittington et al., 1995) thus strongly suggesting that DA modulates both neuronal populations in the cortex. If a similar 


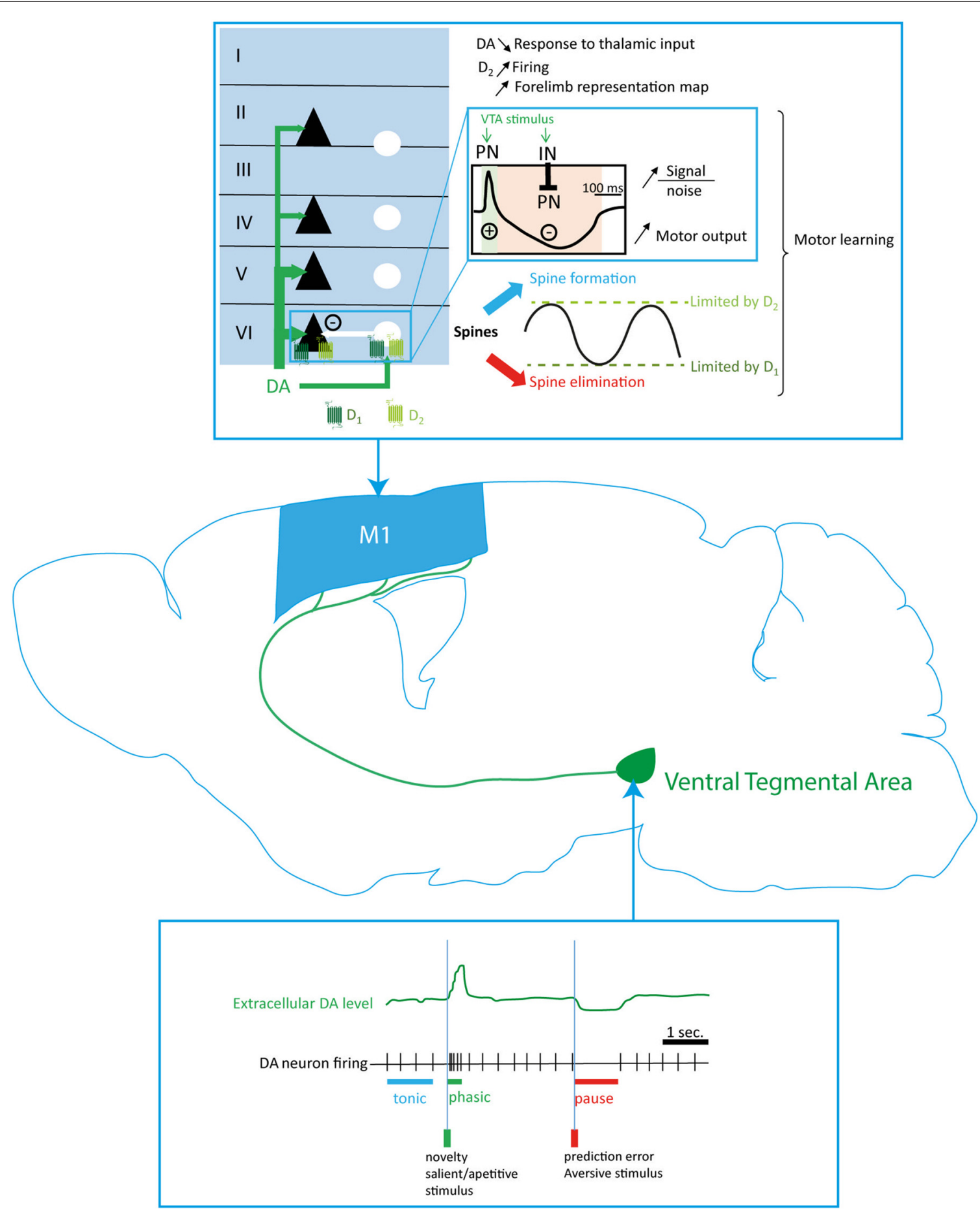

FIGURE 2 | Dopaminergic modulation of the motor cortex function. Dopaminergic innervation of M1 originates in the ventral tegmental area (VTA; green arrows) and preferentially innervates the deep motor cortical layers. Phasic and tonic firing of dopaminergic neurons regulate the dopamine (DA) level in the motor cortex and activate respectively D1 and D2 which are thought to be expressed by the PNs (black triangles) and the INs (white circles) in the motor cortex. Thus, DA innervation exerts a biphasic modulation (blue inlay) of motor cortex neurons to promote motor outputs, increase the signal to noise ratio and regulate the spine turnover necessary to the expression of plasticity and motor learning. DA, dopamine; PN, pyramidal neuron; IN, interneuron.

local network effect of VTA stimulation occurs in M1, one could expect as a result a simultaneous activation of PN and interneurons followed by an inhibition of PN due to interneurons feedforward inhibition. An elegant study from Takashima's group seems to confirm this hypothesis. Indeed, Kunori et al. (2014) demonstrated that VTA stimulation induces 
a fast excitatory-inhibitory response of M1 neurons resulting in the facilitation of motor output to forelimb muscles. Thus, the dopaminergic modulation from the VTA to M1 could synchronize all neuronal activity in the local network, resulting in an increase of the signal to noise ratio in cortico-spinal neurons (Figure 2).

\section{Modulation of Motor Cortex Plasticity by DA}

DA also modulates M1 plasticity and new motor skill learning. Rioult-Pedotti et al. $(1998,2000)$ demonstrated that new motor skill learning reinforces M1 horizontal connections within layer II/III. Interestingly, a specific dopaminergic deafferentation of M1 impairs new motor skill learning in rats but not the execution of a previously acquired motor task (Molina-Luna et al., 2009; Hosp et al., 2011). This learning impairment is associated to a loss of the synaptic reinforcement in M1 and is restored by the injection of D1 or D2 receptor agonists suggesting a synergistic involvement of D1-like and D2-like receptors (Molina-Luna et al., 2009; Hosp et al., 2011). Thus, although no role of D1 receptors was described on M1 activity, they are involved in the modulation of M1 plasticity. This was also described in vitro, since pharmacological blockade of D1 as well as D2 receptor impairs long term potentiation (LTP) in rat M1 slices, suggesting a synergistic effect of D1 and D2 receptors on plasticity in M1 neural networks (Molina-Luna et al., 2009). This mechanism, challenging the classic view of antagonistic effects of D1 receptor and D2 receptor, is mediated via the non-classical phosphoslipase C (PLC) pathway. Indeed, Rioult-Pedotti et al. (2015) demonstrated that activation of PLC in M1 slices of rat prevents DA receptor blockade-induced impairments of plasticity.

At the structural level, DA differentially regulates spines turnover. In adult mice, in vivo D1 receptor blockade with SCH23390 increases spine elimination whereas D2 receptor blockade increases spine formation in M1, suggesting that D1 receptor activation could inhibit spine elimination and that D2 receptor activation could inhibit spine formation (Guo et al., 2015). This is consistent with a previous report in M2 showing that a systemic blockade of D2 receptors by eticlopride enhances the formation of new boutons in M2 induced by a phasic stimulation of the VTA (Mastwal et al., 2014). Nevertheless, these different dopaminergic regulations of spine turnover are not opposed to the synergistic effects on synaptic plasticity described above. Indeed, by setting up a range within which structural plasticity can be expressed, DA could at the same time limit the numbers of irrelevant connections between neurons and prevent aberrant connections (Figure 2). Electrophysiological experiments only showed fewer than $20 \%$ of connectivity among PN despite the fact that PN in the output layers of M1 anatomically contact all neighboring neurons (Sjöström et al., 2001; Kalisman et al., 2005; Biane et al., 2015). Interestingly, a sparsely connected neural network is thought to be the basis for a maximal storage capacity. In a neural networks model optimized for memory storage, the fraction of silent synapses or potent synapses is at least 50\% (Brunel, 2016). Thus, DA modulation of structural plasticity could contribute to maintain a low fraction of synaptic connections between M1 neurons to optimize memory storage and keep specific functional connections between neurons involved in a relevant behavior. Also, if D1 receptor activity or D2 receptor activity is impaired in $\mathrm{M} 1$, the spine turnover could become unstable and structural and synaptic plasticity dampened.

This was confirmed by the demonstration that both D1 and D2 receptors are involved in M1 spine remodeling and synaptic plasticity (Guo et al., 2015). Moreover, local DA depletion in M1 induces spine remodeling in mice as well as motor learning impairment in rats that can be restored by intracortical infusion of levodopa (Molina-Luna et al., 2009; Guo et al., 2015). Altogether, these data suggest that the direct dopaminergic innervation of M1 could regulate structural plasticity.

\section{Modulation of DA Neuronal Activity by External Stimuli: Implication for Motor Cortex Response to Environmental Clues}

Dopaminergic innervation from the VTA to M1 modulates cortical neurons activity and directly impacts M1 synaptic plasticity. This results in an enhancement of neuronal pathways involved in relevant motor outputs to refine new motor skill learning. As such, M1 plays a crucial role in the planning and execution of movements.

DA acts as a key interface between the sensory function and voluntary movements that allow for the selection of motor plans appropriate to the environmental and behavioral contexts. Indeed, dopaminergic neurons are able to switch from a tonic firing pattern to either a pause in firing or a phasic burst of increased activity in response to specific environmental clues (Freeman and Bunney, 1987; Kosobud et al., 1994; Mirenowicz and Schultz, 1996; Schultz, 2010). Thus, VTA dopaminergic neurons mediate signals related to reward and expectation (Eshel et al., 2016; Figure 2). Given that dopaminergic terminals in M1 originates from the VTA, one could assume that a decrease or a pause in dopaminergic tonic firing, such as occurring following the absence of an expected reward, during a fine motor skill learning may decrease excitatory neuronal transmission in the forelimb motor area to prevent the reinforcement of the non-rewarded movement (Hosp et al., 2011; Eshel et al., 2016). Also, according to the classical view of D1 receptor and D2 receptor opposite effects on physiological events, one could assume that a phasic dopaminergic activity arising from the VTA to signal a reward would be crucial to reinforce the successful behavior. Noteworthy, electrical stimulation of the VTA induces a fast M1 neural network depolarization followed by a long duration hyperpolarization, demonstrating that DA can decrease or increase motor cortex activity (Kunori et al., 2014). This biphasic profile is consistent with the changes in the firing rate of the VTA DA neurons in response to a reward omission (Eshel et al., 2016). A cue previously paired with a reward increases instantaneously the firing rate of dopaminergic neurons. When the reward is then omitted, the firing rate of dopaminergic neurons decreases below the baseline rate. Therefore, a behavior could be facilitated or inhibited depending 
on whether it has been rewarded or not, by a dopaminergic signal in M1.

\section{NOREPINEPHRINE MODULATION OF MOTOR CORTEX FUNCTION}

Norepinephrine (NE) is synthetized from DA by the DBH, this enzyme being specifically expressed in the brain by norepinephrinergic fibers. NE is almost exclusively produced and released throughout the brain by a small number of neurons located in a densely packed pontine structure; the Locus Coeruleus (LC; Descarries and Droz, 1970; Swanson and Hartman, 1975). LC neurons exhibit highly ramified dendritic arbors that largely extend beyond the limit of the nucleus (Swanson, 1976; Foote et al., 1983; Shipley et al., 1996). Through this large arborization, NE neurons receive inputs from numerous brain regions including the PFC, the Bed Nucleus of the Stria Terminalis, the Hypothalamus, the dorsal raphe (DR) and the Amygdala (Pickel et al., 1977; Arnsten and GoldmanRakic, 1984; Peyron et al., 1998; Van Bockstaele et al., 1998, 1999).

The diversity of these inputs makes the LC a relay for information from the autonomic nervous system, neuroendocrine nuclei, stress and limbic circuits, as well as higher order cognitive centers (for review, see Chandler, 2016). Indeed, NE is a key neurotransmitter system for the circadian regulation of arousal. LC neurons tonic activity depends on sleep and wakefulness states, while phasic activity is related to stimuli salience. Through the ability of NE neurons to fire at different rates and among different patterns, this neuromodulatory system participates to a wide range of behaviors such as brain arousal and wakefulness, locomotor activity, anxiety and stress response as well as executive functions and decision making processes (Aston-Jones and Bloom, 1981a,b; Arnsten and Contant, 1992; Rajkowski et al., 1994; Aston-Jones et al., 2001; Carter et al., 2010; McCall et al., 2015; Schiemann et al., 2015).

\section{Neuroanatomical Evidence}

The noradrenergic innervation of the brain has been qualitatively described in early studies as a diffuse network of collateralized fibers innervating all neocortical structures, except in the cingulate cortex within which the fibers density has been found higher than in other areas (Fuxe and Ungerstedt, 1968; Jones and Moore, 1977; Jones et al., 1977; Audet et al., 1988). However, it has been shown that NE innervation is segregated in cortical areas (Chandler et al., 2014). LC neurons projecting to the cortex are mostly present in the caudal portion of the nucleus with more than 95\% ipsilateral projection pattern (Waterhouse et al., 1983; Figure 3).

Cortical NE is layer specific (Fuxe and Ungerstedt, 1968; Audet et al., 1988), these early studies concluded that NE innervation was more sparse in the superficial than in the deep layers, although this laminar specificity was more evident in primates than in rodents (Morrison and Foote, 1986; Lewis et al., 1987). More recently, the belief that NE fibers are uniformly distributed in rodents throughout the different cortical structures has been challenged. Indeed, Agster et al. (2013) demonstrated using a stereological approach that the density in
NE varicosities is higher in the rat PFC than in M1. Moreover, they showed that NE innervation density is higher in layer I than in layer V and VI. This heterogeneous distribution of cortical NE innervation suggests that the amount of NE released during LC activation may vary between regions, thus specific cortical areas could be differentially modulated. Consistent with this idea, an elegant study showed that LC neurons projecting to M1 and PFC are not only anatomically segregated in the LC but also that their physiology differs since M1 projecting neurons exhibit lower firing frequencies and responses to glutamate than those projecting to the PFC (Chandler et al., 2014).

NE effects are mediated by $\alpha$-adrenoreceptors and $\beta$-adrenoreceptors (Summers and McMartin, 1993; Ramos and Arnsten, 2007). Three receptor families have been identified depending on the different intracellular cascades they activate. The $\alpha 1$ adrenoceptors ( $\alpha 1$-ARs) activates the PLC and eventually PKC through Gq/11 Protein. The $\alpha 2$ adrenoceptors ( $\alpha 2$-ARs) are coupled to a Gi-protein leading to the reduction of cyclic adenosine monophosphate (cAMP). Eventually, three families of $\beta$ adrenoceptors ( $\beta$-ARs 1-3) have been characterized, each activating a stimulatory $\mathrm{G}$ protein Gs resulting in the elevation of cAMP levels. Noradrenergic receptors $\alpha 1$-ARs, $\beta 1$-ARs and $\beta 3$-ARs are postsynaptic whereas $\alpha 2$-ARs and $\beta 2$-ARs are both pre and post synaptic (O'Donnell, 1993). The three classes of receptors also differ regarding their affinity for NE: $\alpha 2$ (tens of $\mathrm{nM})>\alpha 1(300 \mathrm{nM})>\beta(\mu \mathrm{M})$. Noradrenergic receptors are expressed throughout the cortical layers although a clear demonstration of their expression by neuronal subtype in the motor cortex is still lacking. Nearly all the PN in the PFC express $\beta$-ARs (Rainbow et al., 1984; Goffinet and De Volder, 1985; Goldman-Rakic et al., 1990; Zhou et al., 2013).

\section{Evidence of Motor Cortex Functional Modulation by NE}

Modulation of the LC neurons activity or of NE levels in the brain modifies cortical activity and excitability in rodents and humans. Microdialysis studies conducted in rat described the release of NE in cortical areas through exocytosis (van Veldhuizen et al., 1990, 1994; Chiti and Teschemacher, 2007). Iontophoretical application of NE in the rat primary somatosensory cortex results in the increase of stimulus-evoked cortical neurons responses (Waterhouse and Woodward, 1980; Waterhouse et al., 1980, 1988). This increase in excitatory synaptic responses following NE application is mediated by a1-ARs (Mouradian et al., 1991; Waterhouse et al., 2000). On the opposite, NE facilitates the inhibitory response to GABA stimulation through $\beta$-ARs activation (Waterhouse et al., 1982; Figure 3).

Extracellular recordings performed in M1 layers III to V of anesthetized rats showed that iontophoretic application of $\beta 2$-ARs agonists either decreased or increased putative pyramidal firing rate whereas $\beta 1$-ARs agonists decreased pyramidal firing rate (Lukhanina et al., 2003). These cellular effects of NE in M1 suggest a bimodal modulation of firing activity in M1 by NE (Figure 3). Recently, in vivo patch clamp recordings 


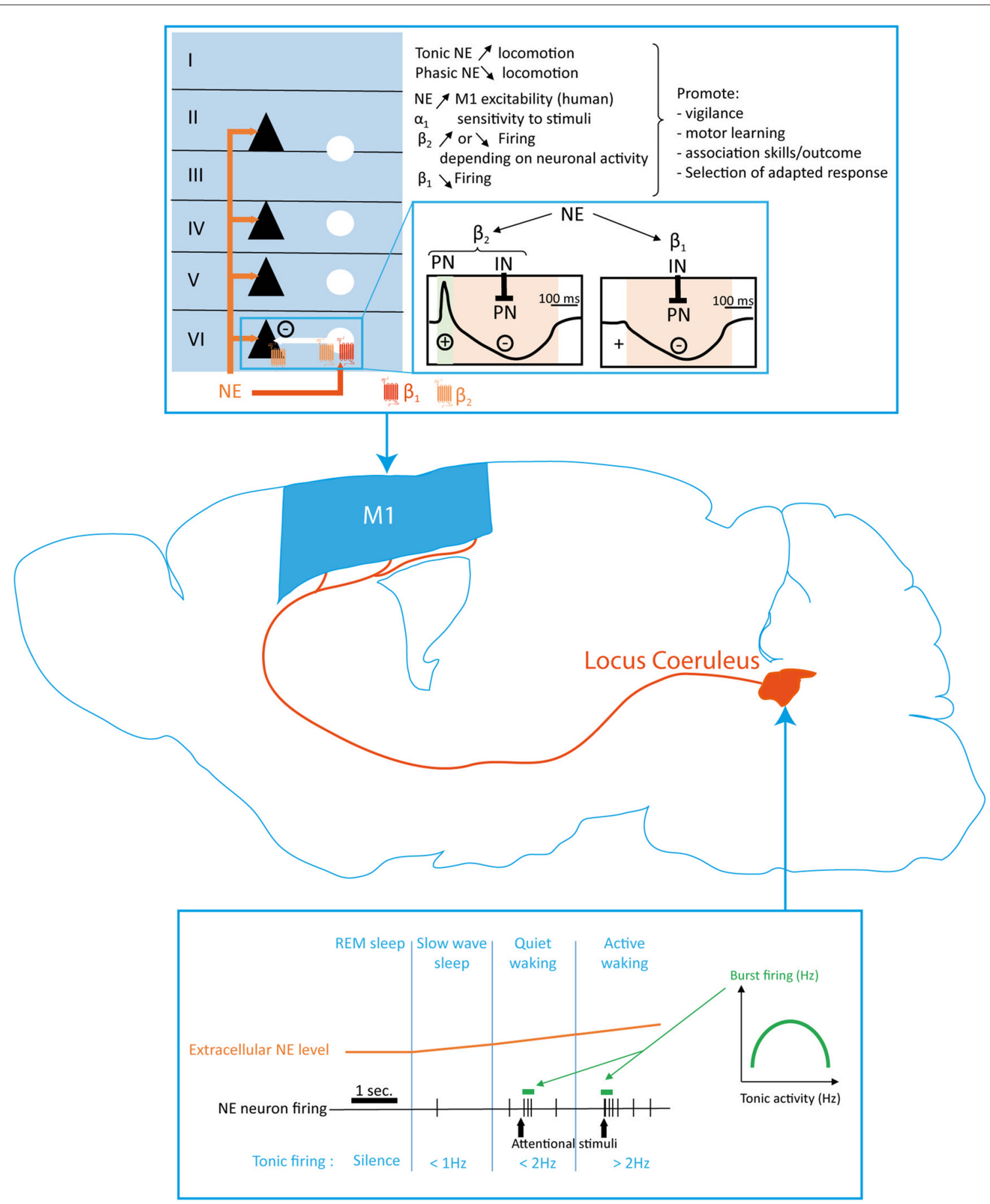

FIGURE 3 | Norepinephrine (NE) modulation of the motor cortex function. NE innervation in M1 originates in the Locus Coeruleus (LC) and terminates homogeneously in all cortical layers. Extracellular NE levels are determined by different neuronal firing frequencies related to the wake/sleep state and firing patterns in response to external stimuli. Tonic and phasic NE release respectively promotes and reduces locomotion. NE exerts its effects in M1 through $\alpha_{1}, \beta_{1}$ and $\beta_{2}$ receptors located on projection neurons (black triangles) and interneurons (white circles). The differential expression of $\beta_{1}$ and $\beta_{2}$ receptors by both neuronal populations (blue inlay) results in two different sequence of excitation/inhibition response in $\mathrm{M} 1$ projection neurons. NE modulation of M1 plays a key role in modulating motor response in accordance to the level of vigilance and attention required by the behavioral situation. NE, norepinephrine; PN, pyramidal neuron; IN, interneuron.

demonstrated that topical application of NE antagonists over the forelimb area of M1 induced a hyperpolarization of layer $\mathrm{V}$ output neurons and decreased their firing rate when the animal is at rest (Schiemann et al., 2015). This is consistent with human data showing an increase of M1 excitability after blocking NE reuptake (Plewnia et al., 2004). Moreover, NE 
induces a tonic depolarization of layer $\mathrm{V}$ neurons during movement, resulting in the enhancement of M1 neurons firing and promoting contralateral forepaw motor coordination (Schiemann et al., 2015). This study suggests that during movement, NE activate a subpopulation of M1 neurons that are otherwise inhibited.

Altogether, these studies demonstrated that NE inputs to the motor cortex maintains excitability and ameliorates the signalto-noise ratio in the structure by promoting $\mathrm{PN}$ firing during movement in order to ensure a correct movement execution (Figure 3).

\section{Modulation of Motor Cortex Plasticity by NE}

In human, blocking of the NE reuptake enhances motor skill learning indicating that $\mathrm{NE}$ can also modulate motor cortex plasticity and suggesting that an increase in NE levels supports LTP (Plewnia et al., 2004). In the visual cortex, Salgado et al. (2012) demonstrated that NE differentially regulates spike timing dependent plasticity (STDP) in the layer II/III. When presynaptic neurons and postsynaptic neurons were stimulated with a negative delay, a high concentration of $\mathrm{NE}$, as a low concentration of NE, triggers LTD. However, for pairings at a short positive delay, a high concentration of NE triggers LTP whereas a low concentration of NE triggers LTD, suggesting that NE is responsible for associative forms of plasticity. Indeed, beta-adrenergic receptors, when activated with agonists, lower the threshold required to induce LTP at synapses between the amygdala and the perirhinal cortex but not at local synapses within the perirhinal cortex (Laing and Bashir, 2014). Amygdala has a key role on emotions processing and motivation, thus implicating NE in modulating plasticity in function of contextual feeling (Janak and Tye, 2015). As such, infusion of $\beta 2$-ARs agonists in the PFC improved the retention of fear memories in rats (Zhou et al., 2013).

Because $\alpha$-ARs and $\beta$-ARs are coupled to different $G$ proteins like DA receptors, one can imagine that their activation differentially regulates the polarity of plasticity. Indeed, antagonizing $\alpha 1$-ARs led to LTP induction for pairings at negative delay whereas antagonizing $\beta$-ARs led to LTD induction at positive delay, suggesting that the formers are responsible for LTD induction whereas the latters are responsible for LTP induction (Salgado et al., 2012). Consistently, bath application of beta-adrenoreceptor agonist in visual cortex slices or PFC slices promotes only LTP at a single cell level with STDP for negative and positive pairings and field potential level with two-input slices preparation whereas bath application of $\alpha 1$-ARs agonist promotes only LTD (Seol et al., 2007; Zhou et al., 2013).

How NE influences motor cortex plasticity has still not been unraveled. In other cortices, NE promotes associative plasticity to link a neuronal pathway to the emotional context during which it has occurred. New motor skill learning is supported by a reinforcement of the synaptic transmission in the layer II/III of M1 (Rioult-Pedotti et al., 1998). Similar to the role of $\beta$-ARs on LTP induction in other cortices, their blockade impairs the acquisition of a novel task in rats (Heron et al., 1996). Therefore, mechanisms by which NE modulates plasticity in M1 seem to closely resemble the ones already demonstrated in other cortical areas.

\section{Modulation of NE Neuronal Activity by External Stimuli: Implication for Motor Cortex Response to Environmental Clues}

LC neurons, like other monoaminergic cells, exhibit multimodal firing patterns in response to environmental and behavioral context and NE activity seems to be coordinated with the activity of other neuromodulators (Aston-Jones and Cohen, 2005). NE containing neurons in both anesthetized and unanesthetized rats spontaneously discharge at $0-5 \mathrm{~Hz}$ with different tonic frequencies interrupted by bursts of activity (Aston-Jones and Bloom, 1981a,b). In brain slices from young rats, NE neurons exhibit a synchronous oscillatory activity due to an electrotonic coupling between dendrites outside the cell body region (Williams et al., 1984; Ishimatsu and Williams, 1996). This coupling decline with age (Alvarez et al., 2002).

Tonic firing in NE neurons is characterized by low frequency, sustained and highly regular state-dependent firing (Figure 3). Changes in firing discharge rate anticipate changes in behavioral state. During waking, increase in tonic pattern frequency (up to $15 \mathrm{~Hz}$ ) is elicited by environmental and behavioral stimuli of arousal and attention as demonstrated in cats and rodents (Hobson et al., 1975; Foote et al., 1980; Aston-Jones and Bloom, 1981a,b). Phasic firing pattern is characterized by 2-3 AP followed by a 300-700 ms silent period. This burst of AP occurs during waking in response to salient sensory stimuli with a latency of 15-70 ms. This response presents a habituation related to repeated stimulus presentation (Aston-Jones and Bloom, 1981b; Aston-Jones et al., 1994). Studies conducted in primates and rodents demonstrated that the firing frequency during phasic activity depends on the level of tonic activity in an inverted U-curve dependent relation (Aston-Jones and Bloom, 1981a; Valentino and Foote, 1988; Rajkowski et al., 1994; Figure 3). Unlike DA multimodal activity that is encoded in different DA extracellular levels corresponding to tonic and phasic firing modes, NE extracellular levels linearly follow the frequency of tonic discharge activity (Florin-Lechner et al., 1996; Berridge and Abercrombie, 1999; Figure 3). For instance, salient stimuli, both appetitive and aversive, induce phasic responses in LC neurons as well as an increase in extracellular NE levels in rodents (Foote et al., 1980; Feenstra et al., 2000, 2001; Feenstra, 2000).

These different state-dependent activation patterns of NE neurons result in the modulation of cortical oscillatory activity. For instance, optogenetic inhibition of the LC neurons in mice enhances the slow wave activity of the cerebral cortex characteristic of a sleeping brain, whereas photoactivation of LC neurons decreases the REM sleep cortical activity pattern and awakes mice (Steriade et al., 1993; Carter et al., 2010). This demonstrates that NE controls the general vigilance state of the brain. Interestingly, during cortical slow wave activity, LC neurons fire during the rising phase of the waves, suggesting that NE enhances cortical excitability (Eschenko et al., 2012). Consistent with this hypothesis, inhibition of the 
NE reuptake by a single oral dose of reboxetine in humans increases M1 excitability (Herwig et al., 2002; Plewnia et al., 2004).

Recent studies suggest that NE neurons are not homogeneous regarding their projection pattern as well as their functional properties. Chandler et al. (2014) demonstrated that PFC and M1 projecting neurons display specific electrophysiological properties depending on their projection target. M1 projecting neurons are less excitable and fire at lower frequencies than PFC projecting neurons, potentially leading to greater NE release in the PFC than in M1.

Multimodal firing patterns of NE neurons allows the generation of responses adapted to the behavioral demand (Schwarz and Luo, 2015). Even though both tonic and phasic firing patterns induce wake from sleep and increase the ratio of wakefulness, only tonic activity increases locomotion and anxiety-like-behavior whereas only phasic NE signaling decreases locomotion (Carter et al., 2010; McCall et al., 2015). Based on their extensive work on LC neuronal firing, AstonJones group developed the adaptive gain theory of NE coding (Aston-Jones and Waterhouse, 2016). According to this view, LC neurons would be phasically activated by decision outcome and thus would promote the execution of adaptive behavioral responses whereas high tonic discharge rates would disrupt low priority behaviors and increase flexibility.

\section{SEROTONIN MODULATION OF MOTOR CORTEX FUNCTION}

Serotonin (5-HT) neurons are found in the Raphe nucleus and innervate almost all the brain structures to promote adaptation of the behavior depending on the environmental context. Thick serotoninergic fibers holding large spherical varicosities are sent by the median raphe whereas thin serotoninergic fibers with small fusiform varicosities originate from the DR (Kosofsky and Molliver, 1987). Neurons of the DR nucleus provide the main source of serotoninergic innervation of the cortex (Jacobs and Azmitia, 1992). They transiently modulate cortical firing rate and firing regularity and pattern depending on environmental context (Jacobs and Azmitia, 1992; Veasey et al., 1997; Ranade and Mainen, 2009; Li et al., 2016). This modulation is mediated by GABAergic, glutamatergic, catecholaminergic and histaminergic inputs from the raphe nucleus itself and structures involved in motor control, cognition and emotions (Jacobs and Azmitia, 1992).

\section{Neuroanatomical Evidence}

A high density of 5-HT fibers has been revealed in early studies in all the frontal cortices and the motor cortex of rats and primates (Vertes, 1991; Wilson and Molliver, 1991). In primates, these fibers predominantly innervate the superficial layers but seem equally distributed throughout the cortical layers in rats (Vertes, 1991; Wilson and Molliver, 1991). Interestingly, the motor cortex is highly innervated by 5 -HT fibers in rats whereas the serotoninergic innervation of the motor cortex is lower than in the somatosensory cortex in primates, suggesting a phylogenetical differentiation of the functionality of 5-HT regulation of behaviors (Vertes, 1991; Wilson and Molliver, 1991; Figure 4).

Serotonin acts via 14 receptors, almost all belonging to the superfamily of $\mathrm{G}$ protein-coupled receptors. They are classified in seven families referred as $5-\mathrm{HT}_{1}$ to $5-\mathrm{HT}_{7}$ and modulate release of neurotransmitters. The cortical structures express mainly receptors from the $5-\mathrm{HT}_{1}$ and $5-\mathrm{HT}_{2}$ families, with a majority of 5- $\mathrm{HT}_{1 \mathrm{~A}}$ (Pazos and Palacios, 1985; Dillon et al., 1991; Celada et al., 2013). $5-\mathrm{HT}_{1 \mathrm{~A}}$ receptor is coupled to a $\mathrm{Gi} / \mathrm{o}$ protein suggesting an inhibitory role on neuronal activity whereas $5-\mathrm{HT}_{2 \mathrm{~A}}$ is coupled to a $\mathrm{Gq}$ protein, suggesting a facilitatory role of neuronal activity.

In the human motor cortex, Joyce et al. (1993) demonstrated that serotoninergic receptors are highly expressed in the superficial layers I/II and weakly expressed in the deepest layers $\mathrm{V}$ and VI, matching the fibers distribution showed in primates (Wilson and Molliver, 1991). More precisely, 5- $\mathrm{HT}_{1 \mathrm{~A}}$ receptors are mainly expressed in layer II/III whereas $5-\mathrm{HT}_{2 \mathrm{~A}}$ showed a uniform laminar distribution (Joyce et al., 1993; Figure 4). Later, double in situ hybridization studies allowed a closer understanding of the organization of the serotoninergic system in the cerebral cortex. At least $50 \%$ of the PN and about $30 \%$ of the GABAergic neurons express either 5- $\mathrm{HT}_{1 \mathrm{~A}}$ and/or 5$\mathrm{HT}_{2 \mathrm{~A}}$ receptors mRNA in the rodent PFC (Santana et al., 2004). Moreover, $80 \%$ of the neurons expressing $5-\mathrm{HT}_{1 \mathrm{~A}}$ receptor also express 5- $\mathrm{HT}_{2 \mathrm{~A}}$ (Amargós-Bosch et al., 2004). Further studies revealed that each of the receptors are expressed in different compartments of the neurons, suggesting that 5-HT can regulate the synaptic input and action potential generation of the same neuron and strongly influence cortical activity (Jakab and Goldman-Rakic, 1998; Cruz et al., 2004).

\section{Evidence for Motor Cortex Functional Modulation by 5-HT}

Both chronic and acute pharmacological blockade of the 5-HT reuptake by the selective 5 -HT reuptake inhibitor (SSRI) paroxetine, in healthy humans increases excitability of the motor cortex as measured by transcranial magnetic stimulation (Loubinoux et al., 2005). Furthermore, during a motor task involving the hand, a single dose of the SSRI fluoxetine enhanced activation of the sensorimotor cortex contralateral to the performing hand (Loubinoux et al., 1999). These data strongly suggest that 5 -HT can facilitate motor outputs. Consistent with this, a 5-HT pharmacological depletion in rats decreased the cortical excitability measured by ICMS, caused a motor maps shrinkage and decreased the number of attempts in a skill reaching task (Scullion et al., 2013). Moreover, electrical stimulation of the DR nucleus lowered the movement threshold measured by ICMS, thus increasing cortical excitability through release of 5-HT (Scullion et al., 2013). These effects were blocked by application of a $5-\mathrm{HT}_{1 \mathrm{~A}}$ antagonist and activation of $5-\mathrm{HT}_{1 \mathrm{~A}}$ receptors with 8-OHDPAT increases the size of the forelimb motor area. Further experiments revealed that activation of $5-\mathrm{HT}_{1 \mathrm{~A}}$ increased layer $\mathrm{V} \mathrm{PN}$ excitation in motor cortex slices and the extent of the motor maps representation (Scullion et al., 2013). These data suggest that 5-HT facilitates motor cortex activation via $5-\mathrm{HT}_{1 \mathrm{~A}}$ receptors (Figure 4). This conclusion is 


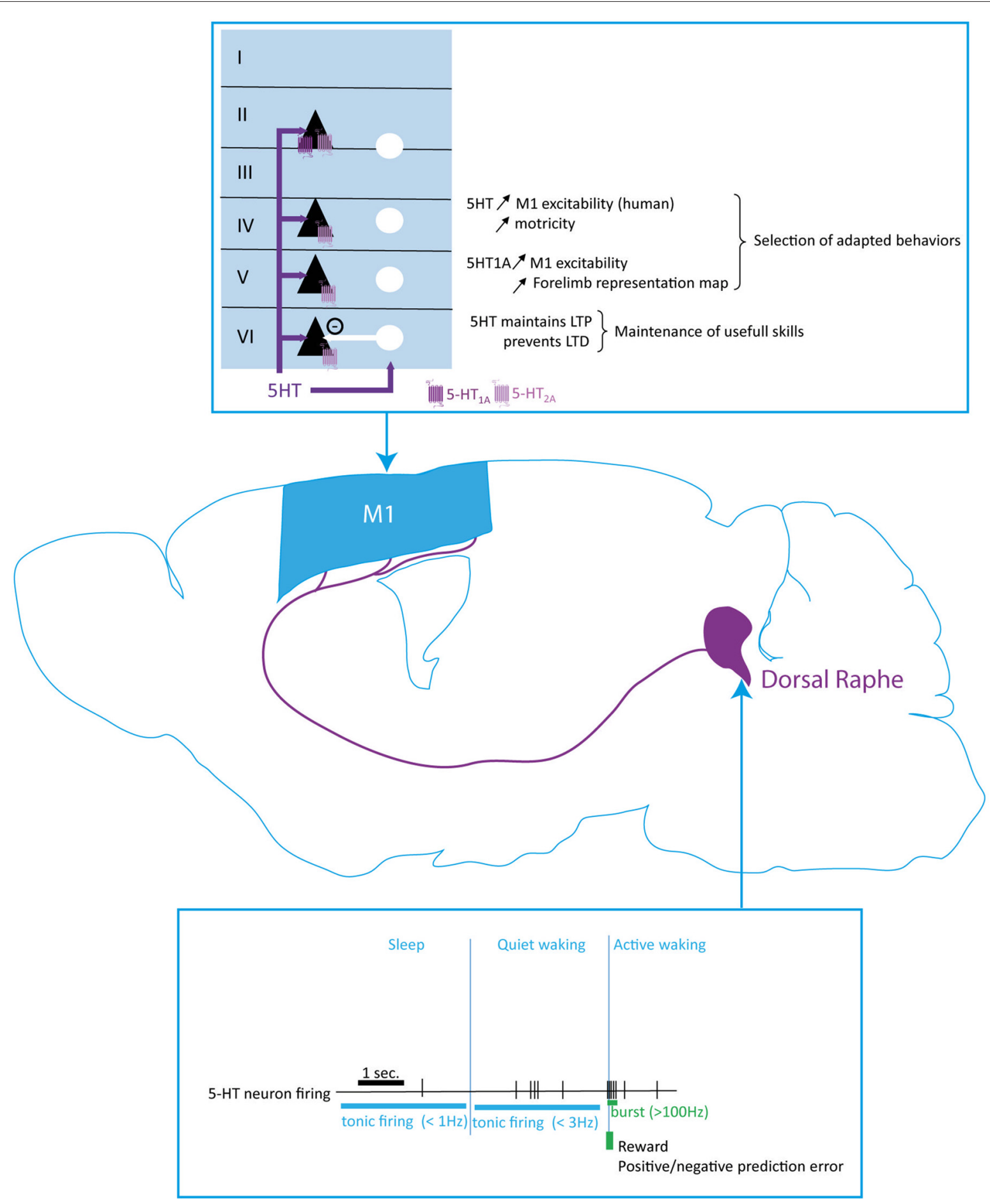

FIGURE 4 | Serotoninergic modulation of the motor cortex function. Serotoninergic neurons from the dorsal raphe (DR) nucleus innervate all cortical layers in M1. The 5-HT neurons different firing frequency and patterns, which are determined by the sleep-wake cycle and response to external stimuli, modifies the extracellular 5-HT level to enhance motor cortex excitability and regulate the maintenance of long term potentiation (LTP). Serotonin plays a key role in the selection of adapted behaviors and maintenance of useful skills. 5-HT, serotonin; PN, pyramidal neuron; IN, interneuron.

however counterintuitive to the Gi/o-coupling of this receptor and the inhibitory effect reported in other cortical structures. For instance, application of 5-HT by air pressure in PFC mice slices inhibits activity of layer V PN projecting to the pons, confirming a previous in vivo study in rats in which stimulation of the DR nucleus inhibits about $2 / 3$ of the PN recorded in the PFC and 
in the secondary motor areas via $5-\mathrm{HT}_{1 \mathrm{~A}}$ receptors (Puig et al., 2005; Avesar and Gulledge, 2012). Also in the visual cortex, 5-HT enhances GABAergic currents recorded in layer II/III PN (Joo et al., 2015). Expansion of the motor maps is regulated by GABAergic activity in M1 (Chakrabarty and Martin, 2005). Cortical GABAergic neurons express 5- $\mathrm{HT}_{1 \mathrm{~A}}$ (Amargós-Bosch et al., 2004; Santana et al., 2004). Therefore, we can hypothesize that the excitatory effects of $5-\mathrm{HT}_{1 \mathrm{~A}}$ in the motor cortex result from inhibition of the GABAergic interneurons. This hypothesis is consistent with in vivo data in rodents demonstrating that a stimulation of the DR nucleus inhibits the GABAergic neurons in the PFC via activation of the $5-\mathrm{HT}_{1 \mathrm{~A}}$ receptors (Puig et al., 2010).

Altogether, these results suggest that 5-HT transmission could exert a strong regulation on neuronal networks in the motor cortex. The tonic regular slow pattern of 5-HT neurons could maintain an optimal degree of activity to precisely shape motor cortical maps and promote dexterity and motor output (Figure 4). Accordingly, activation of $5-\mathrm{HT}_{1 \mathrm{~A}}$ receptors regulate the excitatory-inhibitory balance in PFC slices of mice towards excitation (Meunier et al., 2013).

\section{Modulation of Motor Cortex Plasticity by 5-HT}

Consistent with its bidirectional modulation of cortical neurons activity, 5-HT has been reported to enhance or depress synaptic transmission in different cortical structures. However, studies on the role of 5-HT modulation of motor cortex plasticity points toward a facilitatory role of serotoninergic transmission (Figure 4). Indeed, a single dose of the SSRIs paroxetine or citalopram in humans increased motor skill learning and focal plasticity induced by paired associative stimulus (PAS; Loubinoux et al., 2002; Batsikadze et al., 2013). Consistently, chronic citalopram treatment enhances non-focal transcranial direct stimulation (tDCS)-induced plasticity in humans (Nitsche et al., 2009; Kuo et al., 2016). Interestingly, PAS is thought to act through modulation of synapses whereas tDCS modulates the membrane threshold of the neurons, suggesting that 5-HT promotes plasticity by depolarizing neurons and facilitating synaptic transmission in the cortex (Stefan et al., 2000; Nitsche et al., 2008). This is consistent with recent findings showing that activation of $5-\mathrm{HT}_{1 \mathrm{~A}}$ receptors significantly depolarizes layer $\mathrm{V}$ PN and lowers the threshold to induce spike in motor cortex slices of rats (Scullion et al., 2013). Furthermore, 5-HT also enhances LTP induction in visual cortex slices of adult rats via enhancement of NMDA currents (Joo et al., 2015).

Interestingly, citalopram also converts tDCS-induced LTD into LTP in human motor cortex and abolishes PAS-induced LTD, indicating that 5-HT prevents motor cortex synapses to express LTD (Batsikadze et al., 2013; Kuo et al., 2016). Furthermore, a prolongation of tDCS-induced plasticity by 5-HT has recently been demonstrated (Kuo et al., 2016). These results strongly suggest that 5-HT transmission in the motor cortex is important for motor memory retention. However, a recent report showed no impairment in motor skills acquisition or in the consequent motor maps enlargement after a 5-HT depletion suggesting that 5 -HT has no role or a minor role in motor learning (Scullion et al., 2013).

Altogether, these studies indicate that 5-HT transmission in the motor cortex increases the overall excitability of the neurons to facilitate LTP induction and prevent LTD induction. By these mechanisms, 5-HT could be necessary to retain a newly acquired motor skill. However, 5-HT could have only a minor role on motor skill acquisition per se.

\section{Modulation of 5-HT Neuronal Activity by External Stimuli: Implication for Motor Cortex Response to Environmental Clues}

DR nucleus 5-HT neurons strongly innervate the motor cortex and control neuronal activity and plasticity, but seem to have only a minor role on motor learning. Like DA and NE, serotonergic cells display two firing patterns, i.e., tonic and phasic, that code for contextual information (Figure 4). Tonic firing is characterized by a highly regular firing rate at frequencies comprised between $0.1 \mathrm{~Hz}$ and $3 \mathrm{~Hz}$ in brain slices from rats as well as in behaving cats and rats (Vandermaelen and Aghajanian, 1983; Veasey et al., 1997; Ranade and Mainen, 2009). A fast-firing population of DR neurons has been described, exhibiting tonic firing frequencies up to $17 \mathrm{~Hz}$ in rodents (Allers and Sharp, 2003; Kocsis et al., 2006; Hajós et al., 2007). Phasic firing consists in a burst of 2-4 AP with an frequency above $100 \mathrm{~Hz}$ (Allers and Sharp, 2003; Kirby et al., 2003; Kocsis et al., 2006; Hajós et al., 2007; Schweimer and Ungless, 2010).

The firing rate shows a strong sleep-wake-arousal cycle with a decreasing firing rate during sleep and increased firing rate during quiet wake as studied in freely moving cats and rodents (Veasey et al., 1997; Ranade and Mainen, 2009). Serotoninergic neurons from the DR nucleus respond to different contextual clues, either by an increase in their firing rate or a shift from tonic to phasic firing pattern. Indeed, during task engagement, the firing rate of these neurons increases and can switch from the tonic to the phasic pattern during motor challenge or reward acquisition (Veasey et al., 1997; Ranade and Mainen, 2009; Li et al., 2016). For instance, 5-HT neurons firing rate increases during odor or sound discrimination to engage in a rewarding task (Ranade and Mainen, 2009; Matias et al., 2017). Interestingly, optogenetic inhibiton of 5-HT neurons in the DR of rats slows reversal learning (Matias et al., 2017). These studies thus suggest that 5-HT codes for cognitive flexibility in the brain. Serotoninergic neurons activity is also enhanced during reward seeking and expectation and a photoactivation of these neurons enhances patience for reward in rats without increasing the saliency of the expected reward (Ranade and Mainen, 2009; Miyazaki et al., 2014; Li et al., 2016). However, no significant changes in 5-HT neurons have been detected after punishment, suggesting that 5 -HT encodes reward rather than saliency. In rodents, these neurons also respond to negative or positive violation of the reward prediction error as well as unexpected events (Li et al., 2016; Matias et al., 2017). Altogether, these studies suggest that 5-HT respond to contextual changes to organize selection of a behavior based on the contextual 


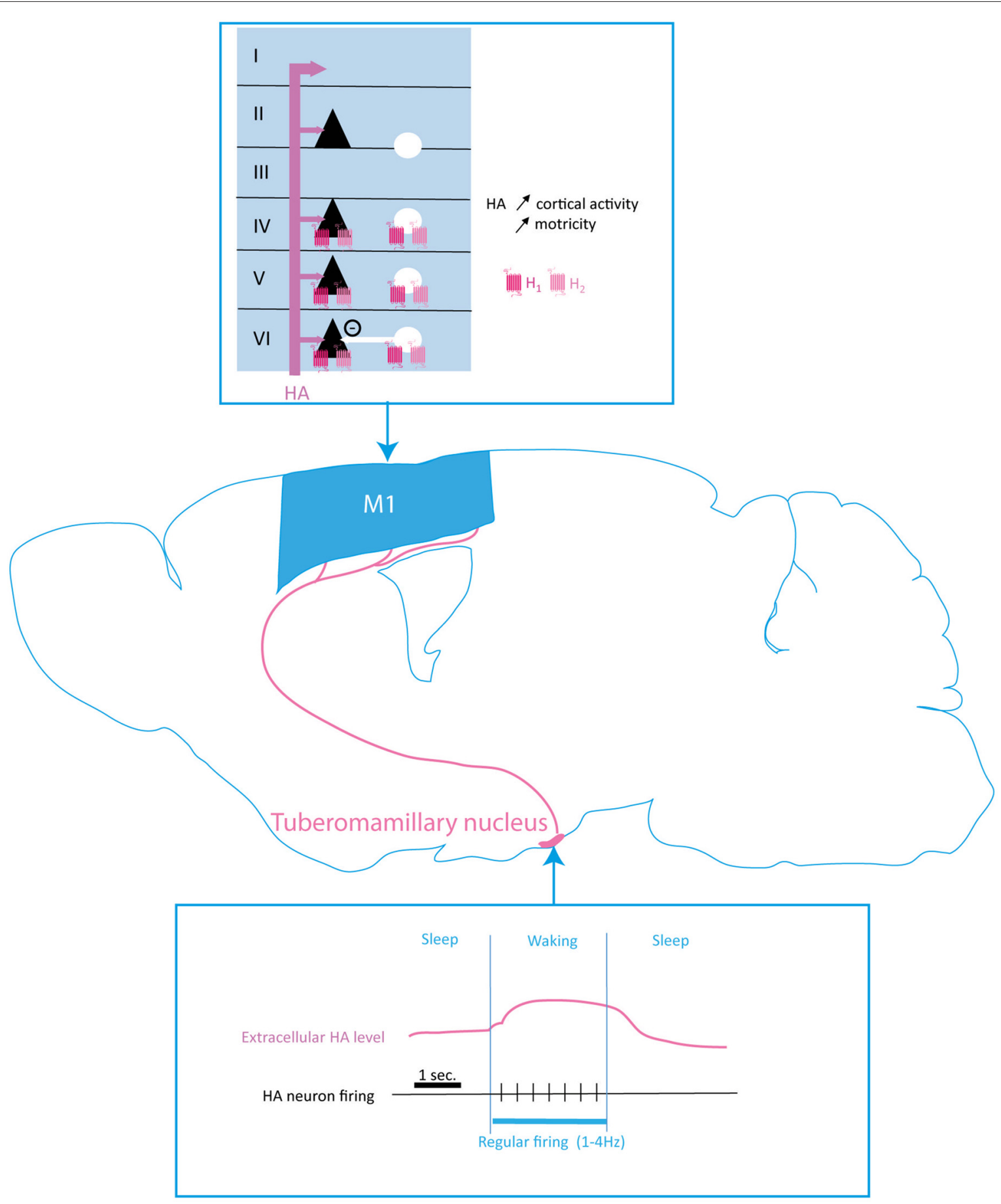

FIGURE 5 | Histaminergic modulation of the motor cortex function. Histamine (HA) input originates in the tuberomamillary nucleus (TMN) and projects to all M1 layers with higher fiber density found in layer I. HA firing and extracellular levels are correlated to sleep/waking rhythm, HA being released tonically during waking. H1 and $\mathrm{H} 2$ receptors are both expressed by projection neurons (black triangles) and interneurons (white circles). HA increases cortical activity and motricity. HA, histamine; $\mathrm{PN}$, pyramidal neuron; IN, interneuron.

outcome. In the motor cortex, this signal could favor the selection of already acquired motor actions in a repertoire based on their utility. If a motor act is useful and keeps being rewarded as expected or better than expected, 5-HT maintains the heightened synaptic transmission between the neuronal pathways involved. However, when a motor behavior becomes useless because the outcome is worse than expected, 5-HT will promote seeking of a new behavior by disrupting the previously 
reinforced synaptic pathway and enhancing flexibility in the cortical area.

\section{HISTAMINE MODULATION OF MOTOR CORTEX FUNCTION}

Unlike other monoamines, brain histamine (HA) did not receive attention until the neuroanatomic characterization of histaminergic neurons by the groups of Wada and Panula (Watanabe et al., 1983, 1984; Hayashi et al., 1984; Panula et al., 1984). As a result of the late attention given to HA neurotransmission, only sparse information is available on cortical HA function and even fewer specifically on motor cortex HA modulation. Thus, this section will mostly integrate current knowledge regarding cortical HA.

Histaminergic neurons, located in the tuberomamillary nucleus (TMN), send projections all over the central nervous system in rats, mice and humans (Wilcox and Seybold, 1982; Steinbusch et al., 1986; Wouterlood et al., 1986; Ericson et al., 1987; Panula et al., 1990; Parmentier et al., 2016). Two main bundles of axons send a large arborization to the cortex among other brain structures (Figure 5). Most cortical regions receive a moderately dense or sparse histaminergic input (Haas et al., 2008). The density of HA terminals differs across layers, being denser in layer I whereas evenly distributed across other layers (Panula et al., 1989, 1990; Manning et al., 1996).

HA is synthetized from histidine through the oxidative decarboxylation by histidine-decarboxylase (HDC). The rate of this synthesis depends on the bioavailability of histidine, which is taken up into the neurons through L-amino acid transporters. HA is stored in the soma of neurons and in axons varicosities. Similar to other monoamines, the internalization of HA into vesicles is achieved by the vesicular monoamine transporter VMAT-2 (Merickel and Edwards, 1995; Weihe and Eiden, 2000). HA release is exocytotic and both release and synthesis are under the control of presynaptic $\mathrm{H} 3$ autoreceptors located on soma and axonal varicosities (Arrang et al., 1983, 1987; Prast et al., 1994).

The activity of HA neurotransmission follows the circadian rhythm (Figure 5). Indeed, microdialysis and electrophysiology studies showed that HA neurons firing as well as HA release present a marked circadian rhythmicity (Mochizuki et al., 1992). Projections from the preoptic area, the septum, the subiculum, the dorsal tegmentum and the PFC target HA neurons and modulate their activity (Wouterlood et al., 1987, 1988; Wouterlood and Gaykema, 1988). TMN also receives projections from monoaminergic nuclei leading to an increase of HA neurons activity. Indeed, NE projections to TMN, through $\alpha 2$-ARs activation, remove the local GABA inhibition of HA neurons (Stevens et al., 2004).

Cortically-projecting HA neurons recorded in anesthetized rats exhibit a constitutive slow regular firing pattern at a frequency of 1-4 Hz (Reiner and McGeer, 1987). In freely moving animals, the activity of HA neurons follows the circadian rhythm, firing occurs during waking and TMN neurons are silent during sleep (Lin, 2000; John et al., 2004; Takahashi et al., 2006; Parmentier et al., 2016).
HA binds to four metabotropic receptors (H1R to H4R), H4R is mainly found peripherically whereas H1R-H3R are expressed in the brain (Haas et al., 2008; Hu and Chen, 2017). In the cortex, H1R and H2R are found postsynaptically. The H1R is coupled to the $\mathrm{Gq} / 11$ protein and phospholipase $\mathrm{C}$ and the $\mathrm{H} 2 \mathrm{R}$ is coupled to Gs and stimulates adenylyl cyclase resulting in an increase of intracellular cAMP (Haas and Panula, 2003). The $\mathrm{H} 3 \mathrm{R}$ is presynaptic on histaminergic neurons as well as on other neurons and postsynaptic in the basal ganglia. H3R is coupled to Gi/o leading to the inhibition of adenylyl cyclase (Hu and Chen, 2017). In the PFC, H3R is also expressed on projecting glutamate neurons (Drutel et al., 2001; Panula and Nuutinen, 2013).

Despite the late anatomical characterization of brain HA, early studies using iontophoretic application of HA agonists suggested the histaminergic modulation of cortical activity (Phillis et al., 1968; Sastry and Phillis, 1976a,b; Haas and Wolf, 1977). Moreover, a recent study investigated the effect of $\mathrm{HA}$ on DA, NE and 5-HT transmission in the rat PFC and demonstrated that HA induced increased levels of all three amines aforementioned associated to an increase of neuronal firing restricted to the VTA (Flik et al., 2015).

The circadian activity of HA neurons leads to the modulation of circadian motor activity as well as feeding behaviors (Inzunza et al., 2000; Lozeva et al., 2000; Tuomisto et al., 2001; Haas and Panula, 2003; Meynard et al., 2005; Valdés et al., 2005). Experimental alterations of HA transmission result in motor impairments including a decrease in locomotor activity and a reduction of exploratory behavior in response to a novel environment (Inoue et al., 1996; Toyota et al., 2002; Parmentier et al., 2016). However, this motor impairment could be explained by the well documented innervation of basal ganglia by HA projections.

Altogether, these data suggest that HA modulates the activity of motor cortex, and could also control other monoamine transmission to cortical neurons (Figures 5, 6). The circadian rhythmicity of HA release as well as its role in wakefulness and sleep state could lead to speculate that HA could play a major role in adjusting cortical activity to match the level of functional outcome required by the attentional state.

\section{CONCLUSION}

Monoamines are key mediators of arousal, attention and motivation. Their firing pattern enables a direct encoding of different states thus promoting or repressing the selection of actions adapted to the behavioral context. Current knowledge on monoamine in M1 clearly demonstrates their individual role in coding behaviorally relevant sensory information to adjust motor cortex activity and influence the selection of adapted motor responses. In addition, monoamines interact by regulating each other's activity as well as by sharing common signaling pathways in the target neuron (Figure 6). Motor learning is associated to structural and functional changes in M1, thus the ability of monoamines to modulate M1 plasticity suggest that they can play a major role in the acquisition of new motor skills (RioultPedotti et al., 2000; Kleim et al., 2004; Monfils and Teskey, 2004; Monfils et al., 2005). Other neuromodulatory transmitter systems 

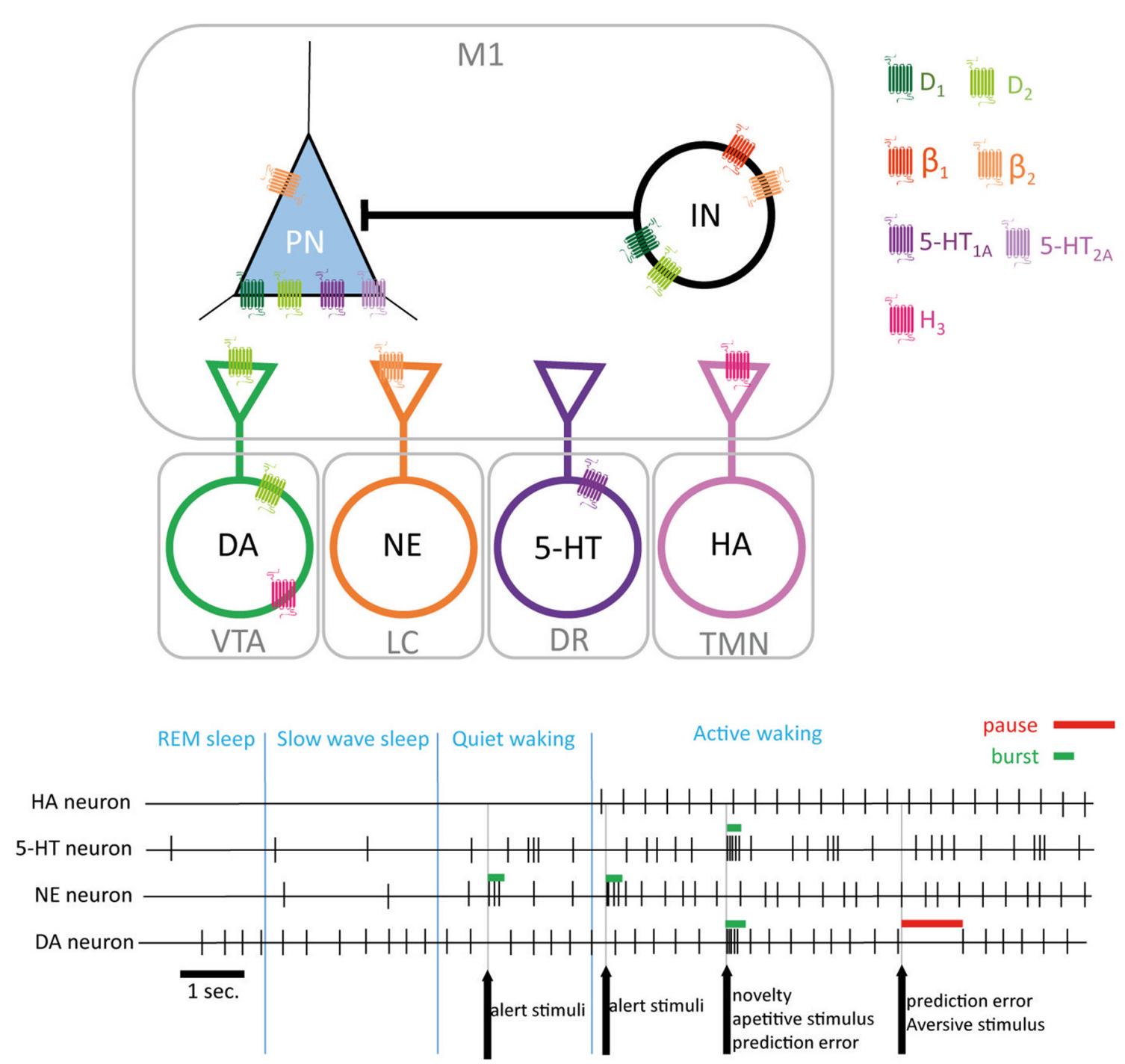

FIGURE 6 | Monoaminergic modulation of M1. Monoamines projecting to M1 interact at pre and post synaptic levels both on pyramidal neurons (PN) and interneurons (IN). Extracellular levels of monoamines are related to sleep/wake states (encoded by tonic firing frequency in HA, 5-HT and NE neurons) and to environmental stimuli supporting attentional/alert information (encoded by bursts or pause in the firing activity by 5-HT, E and DA neurons). DA, dopamine; NE, norepinephrine; 5-HT, serotonin; HA, histamine; M1, primary motor cortex; VTA, ventral tegmental area; LC, locus coeruleus; DR, dorsal raphe; TMN, tuberomamillary nucleus.

are known to shape cortical network activity (Gu, 2002). Indeed, the major role of acetylcholine in neocortex modulation has been well reviewed (Lucas-Meunier et al., 2003; Jones, 2004). More recently, the key role of acetylcholine in motor skill learning has been more closely investigated. Indeed, acetylcholine modulates the reorganization of cortical maps following motor training (Conner et al., 2003, 2010; Ramanathan et al., 2009, 2015). Moreover, muscarinic receptors have been shown to be involved in motor cortex activity and plasticity (Desai and Walcott, 2006; Tian et al., 2014; Hedrick and Waters, 2015). Given the interplay that exist between acetylcholine and DA in other brain regions (Calabresi et al., 2006), it would be particularly valuable to investigate the cross-talk between acetylcholine and monoamines in the motor cortex.
Parkinson's disease (PD) is a progressive neurodegenerative disorder characterized by deficits in motor control and motor learning, although non motor symptoms are also present. The loss of dopaminergic nigrostriatal pathway is the hallmark of $\mathrm{PD}$, this have led to a focus of investigations on the basal ganglia dysfunction in models of nigro-striatal DA depletion. However, the pathological process also involves serotoninergic and histaminergic systems alterations along with an important loss of noradrenergic neurons in the LC (Mann and Yates, 1983; German et al., 1992; Rinne et al., 2002; Marien et al., 2004; Kish et al., 2008; Politis et al., 2010). Moreover, impairments in M1 function have been described in PD patients as well as in PD models (Brown et al., 2009; Guo et al., 2015). In addition to impairments of M1 resulting from a dysfunction of the feedback 
exerted by basal ganglia on the thalamo-cortical feedback, some local impairments in monoamines have been described. Indeed, a decrease in DA, NE and 5-HT terminals in motor cortical regions in brains from $\mathrm{PD}$ patients have been described (Gaspar et al., 1991; Loane et al., 2013). More recently, it was shown that NE as well as 5-HT levels are decreased in M1 from PD patients (Gesi et al., 2000; Marien et al., 2004; Rommelfanger and Weinshenker, 2007). In addition, although no direct evidence indicates any changes in M1 histaminergic system in PD, the decrease of HNMT enzymatic activity observed in some PD patients suggest that a decreased HA degradation might occur leading to alterations of M1 modulation by HA in PD patients (Agúndez et al., 2008; Palada et al., 2012).

Given the increasing hints pointing towards a major role of monoamines in shaping motor responses adapted to behavioral context by controlling the local inhibitory-excitatory network

\section{REFERENCES}

Agster, K. L., Mejias-Aponte, C. A., Clark, B. D., and Waterhouse, B. D. (2013). Evidence for a regional specificity in the density and distribution of noradrenergic varicosities in rat cortex. J. Comp. Neurol. 521, 2195-2207. doi: 10.1002/cne. 23270

Agúndez, J. A., Luengo, A., Herráez, O., Martínez, C., Alonso-Navarro, H., Jimenez-Jimenez, F. J., et al. (2008). Nonsynonymous polymorphisms of histamine-metabolising enzymes in patients with Parkinson's disease. Neuromolecular Med. 10, 10-16. doi: 10.1007/s12017-007-8017-7

Allers, K. A., and Sharp, T. (2003). Neurochemical and anatomical identification of fast- and slow-firing neurones in the rat dorsal raphe nucleus using juxtacellular labelling methods in vivo. Neuroscience 122, 193-204. doi: 10.1016/s03064522(03)00518-9

Alvarez, V. A., Chow, C. C., Van Bockstaele, E. J., and Williams, J. T. (2002). Frequency-dependent synchrony in locus ceruleus: role of electrotonic coupling. Proc. Natl. Acad. Sci. U S A 99, 4032-4036. doi: 10.1073/pnas. 062716299

Amargós-Bosch, M., Bortolozzi, A., Puig, M. V., Serrats, J., Adell, A., Celada, P., et al. (2004). Co-expression and in vivo interaction of serotonin $1 \mathrm{~A}$ and serotonin2A receptors in pyramidal neurons of prefrontal cortex. Cereb. Cortex 14, 281-299. doi: 10.1093/cercor/bhg128

Anderson, C. T., Sheets, P. L., Kiritani, T., and Shepherd, G. M. (2010). Sublayerspecific microcircuits of corticospinal and corticostriatal neurons in motor cortex. Nat. Neurosci. 13, 739-744. doi: 10.1038/nn.2538

Arnsten, A. F., and Contant, T. A. (1992). $\alpha-2$ adrenergic agonists decrease distractibility in aged monkeys performing the delayed response task. Psychopharmacology (Berl) 108, 159-169. doi: 10.1007/bf02245302

Arnsten, A. F., and Goldman-Rakic, P. S. (1984). Selective prefrontal cortical projections to the region of the locus coeruleus and raphe nuclei in the rhesus monkey. Brain Res. 306, 9-18. doi: 10.1016/0006-8993(84)90351-2

Arrang, J. M., Garbarg, M., and Schwartz, J. C. (1983). Auto-inhibition of brain histamine release mediated by a novel class (H3) of histamine receptor. Nature 302, 832-837. doi: 10.1038/302832a0

Arrang, J. M., Garbarg, M., and Schwartz, J. C. (1987). Autoinhibition of histamine synthesis mediated by presynaptic H3-receptors. Neuroscience 23, 149-157. doi: 10.1016/0306-4522(87)90279-x

Aston-Jones, G., and Bloom, F. E. (1981a). Activity of norepinephrine-containing locus coeruleus neurons in behaving rats anticipates fluctuations in the sleepwaking cycle. J. Neurosci. 1, 876-886.

Aston-Jones, G., and Bloom, F. E. (1981b). Norepinephrine-containing locus coeruleus neurons in behaving rats exhibit pronounced responses to non-noxious environmental stimuli. J. Neurosci. 1, 887-900.

Aston-Jones, G., and Cohen, J. D. (2005). An integrative theory of locus coeruleusnorepinephrine function: adaptive gain and optimal performance. Annu. Rev. Neurosci. 28, 403-450. doi: 10.1146/annurev.neuro.28.061604.135709 in $\mathrm{M} 1$, it appears necessary to better understand the exact role of each monoamines in this highly organized network as well as their reciprocal interaction in physiological as well as pathological conditions. Indeed, the monoamine interplay in regulating M1 function suggests that any pathology unbalancing one of the monoamine could potentially impact homeostasis of all the other monoaminergic systems in the brain, including M1. Thus, the tight regulation of M1 activity and plasticity by monoamines could be altered, leading to impairments in motor learning and context-adapted motor responses.

\section{AUTHOR CONTRIBUTIONS}

MB-M initiated the writing of the review, designed the organization of the manuscript. Both authors (MB-M and CV) equally contributed to the writing of the manuscript.

Aston-Jones, G., Chen, S., Zhu, Y., and Oshinsky, M. L. (2001). A neural circuit for circadian regulation of arousal. Nat. Neurosci. 4, 732-738. doi: 10.1038/89522

Aston-Jones, G., Rajkowski, J., Kubiak, P., and Alexinsky, T. (1994). Locus coeruleus neurons in monkey are selectively activated by attended cues in a vigilance task. J. Neurosci. 14, 4467-4480.

Aston-Jones, G., and Waterhouse, B. (2016). Locus coeruleus: from global projection system to adaptive regulation of behavior. Brain Res. 1645, 75-78. doi: 10.1016/j.brainres.2016.03.001

Audet, M. A., Doucet, G., Oleskevich, S., and Descarries, L. (1988). Quantified regional and laminar distribution of the noradrenaline innervation in the anterior half of the adult rat cerebral cortex. J. Comp. Neurol. 274, 307-318. doi: 10.1002/cne.902740302

Avesar, D., and Gulledge, A. T. (2012). Selective serotonergic excitation of callosal projection neurons. Front. Neural Circuits 6:12. doi: 10.3389/fncir.2012.00012

Awenowicz, P. W., and Porter, L. L. (2002). Local application of dopamine inhibits pyramidal tract neuron activity in the rodent motor cortex. J. Neurophysiol. 88, 3439-3451. doi: 10.1152/jn.00078.2002

Badrinarayan, A., Wescott, S. A., Vander Weele, C. M., Saunders, B. T., Couturier, B. E., Maren, S., et al. (2012). Aversive stimuli differentially modulate real-time dopamine transmission dynamics within the nucleus accumbens core and shell. J. Neurosci. 32, 15779-15790. doi: 10.1523/jneurosci. 3557-12.2012

Barbas, H., and García-Cabezas, M. Á. (2015). Motor cortex layer 4: less is more. Trends Neurosci. 38, 259-261. doi: 10.1016/j.tins.2015.03.005

Batsikadze, G., Paulus, W., Kuo, M.-F., and Nitsche, M. A. (2013). Effect of serotonin on paired associative stimulation-induced plasticity in the human motor cortex. Neuropsychopharmacology 38, 2260-2267. doi: 10.1038/npp. 2013.127

Benoit-Marand, M., Jaber, M., and Gonon, F. (2000). Release and elimination of dopamine in vivo in mice lacking the dopamine transporter: functional consequences. Eur. J. Neurosci. 12, 2985-2992. doi: 10.1046/j.1460-9568.2000. 00155.x

Berridge, C. W., and Abercrombie, E. D. (1999). Relationship between locus coeruleus discharge rates and rates of norepinephrine release within neocortex as assessed by in vivo microdialysis. Neuroscience 93, 1263-1270. doi: 10.1016/s0306-4522(99)00276-6

Biane, J. S., Scanziani, M., Tuszynski, M. H., and Conner, J. M. (2015). Motor cortex maturation is associated with reductions in recurrent connectivity among functional subpopulations and increases in intrinsic excitability. J. Neurosci. 35, 4719-4728. doi: 10.1523/jneurosci.2792-14.2015

Brown, A. R., Hu, B., Antle, M. C., and Teskey, G. C. (2009). Neocortical movement representations are reduced and reorganized following bilateral intrastriatal 6-hydroxydopamine infusion and dopamine type-2 receptor antagonism. Exp. Neurol. 220, 162-170. doi: 10.1016/j.expneurol.2009.08.015

Brunel, N. (2016). Is cortical connectivity optimized for storing information? Nat. Neurosci. 19, 749-755. doi: 10.1038/nn.4286 
Calabresi, P., Picconi, B., Parnetti, L., and Di Filippo, M. (2006). A convergent model for cognitive dysfunctions in Parkinson's disease: the critical dopamineacetylcholine synaptic balance. Lancet Neurol. 5, 974-983. doi: 10.1016/s14744422(06)70600-7

Camps, M., Kelly, P. H., and Palacios, J. M. (1990). Autoradiographic localization of dopamine D 1 and D 2 receptors in the brain of several mammalian species. J. Neural Transm. Gen. Sect. 80, 105-127. doi: 10.1007/BF01257077

Carter, M. E., Yizhar, O., Chikahisa, S., Nguyen, H., Adamantidis, A., Nishino, S., et al. (2010). Tuning arousal with optogenetic modulation of locus coeruleus neurons. Nat. Neurosci. 13, 1526-1533. doi: 10.1038/nn.2682

Celada, P., Puig, M. V., and Artigas, F. (2013). Serotonin modulation of cortical neurons and networks. Front. Integr. Neurosci. 7:25. doi: 10.3389/fnint.2013. 00025

Chakrabarty, S., and Martin, J. H. (2005). Motor but not sensory representation in motor cortex depends on postsynaptic activity during development and in maturity. J. Neurophysiol. 94, 3192-3198. doi: 10.1152/jn.004 24.2005

Chandler, D. J. (2016). Evidence for a specialized role of the locus coeruleus noradrenergic system in cortical circuitries and behavioral operations. Brain Res. 1641, 197-206. doi: 10.1016/j.brainres.2015.11.022

Chandler, D. J., Gao, W. J., and Waterhouse, B. D. (2014). Heterogeneous organization of the locus coeruleus projections to prefrontal and motor cortices. Proc. Natl. Acad. Sci. U S A 111, 6816-6821. doi: 10.1073/pnas. 1320827111

Chergui, K., Suaud-Chagny, M. F., and Gonon, F. (1994). Nonlinear relationship between impulse flow, dopamine release and dopamine elimination in the rat brain in vivo. Neuroscience 62, 641-645. doi: 10.1016/0306-4522(94)90465-0

Chiti, Z., and Teschemacher, A. G. (2007). Exocytosis of norepinephrine at axon varicosities and neuronal cell bodies in the rat brain. FASEB J. 21, 2540-2550. doi: 10.1096/fj.06-7342com

Cho, R. H., Segawa, S., Mizuno, A., and Kaneko, T. (2004a). Intracellularly labeled pyramidal neurons in the cortical areas projecting to the spinal cord. I. Electrophysiological properties of pyramidal neurons. Neurosci. Res. 50, 381-394. doi: 10.1016/s0168-0102(04)00210-x

Cho, R. H., Segawa, S., Okamoto, K., Mizuno, A., and Kaneko, T. (2004b). Intracellularly labeled pyramidal neurons in the cortical areas projecting to the spinal cord. II. Intra- and juxta-columnar projection of pyramidal neurons to corticospinal neurons. Neurosci. Res. 50, 395-410. doi: 10.1016/j.neures.2004. 08.007

Ciliax, B. J., Heilman, C., Demchyshyn, L. L., Pristupa, Z. B., Ince, E., Hersch, S. M., et al. (1995). The dopamine transporter: immunochemical characterization and localization in brain. J. Neurosci. 15, 1714-1723.

Conner, J. M., Culberson, A., Packowski, C., Chiba, A. A., and Tuszynski, M. H. (2003). Lesions of the Basal forebrain cholinergic system impair task acquisition and abolish cortical plasticity associated with motor skill learning. Neuron 38, 819-829. doi: 10.1016/s0896-6273(03)00288-5

Conner, J. M., Kulczycki, M., and Tuszynski, M. H. (2010). Unique contributions of distinct cholinergic projections to motor cortical plasticity and learning. Cereb. Cortex 20, 2739-2748. doi: 10.1093/cercor/bhq022

Constantinidis, C., and Goldman-Rakic, P. S. (2002). Correlated discharges among putative pyramidal neurons and interneurons in the primate prefrontal cortex. J. Neurophysiol. 88, 3487-3497. doi: 10.1152/jn.00188.2002

Cruz, D. A., Eggan, S. M., Azmitia, E. C., and Lewis, D. A. (2004). Serotonin1A receptors at the axon initial segment of prefrontal pyramidal neurons in schizophrenia. Am. J. Psychiatry 161, 739-742. doi: 10.1176/appi.ajp.161.4.739

Desai, N. S., and Walcott, E. C. (2006). Synaptic bombardment modulates muscarinic effects in forelimb motor cortex. J. Neurosci. 26, 2215-2226. doi: 10.1523/jneurosci.4310-05.2006

Descarries, L., and Droz, B. (1970). Intraneural distribution of exogenous norepinephrine in the central nervous system of the rat. J. Cell Biol. 44, 385-399. doi: $10.1083 /$ jcb.44.2.385

Descarries, L., Lemay, B., Doucet, G., and Berger, B. (1987). Regional and laminar density of the dopamine innervation in adult rat cerebral cortex. Neuroscience 21, 807-824. doi: 10.1016/0306-4522(87)90038-8

Dillon, K. A., Gross-Isseroff, R., Israeli, M., and Biegon, A. (1991). Autoradiographic analysis of serotonin $5-\mathrm{HT}_{1 \mathrm{~A}}$ receptor binding in the human brain postmortem: effects of age and alcohol. Brain Res. 554, 56-64. doi: 10.1016/0006-8993(91)90171-q
Dreyer, J. K., Herrik, K. F., Berg, R. W., and Hounsgaard, J. D. (2010). Influence of phasic and tonic dopamine release on receptor activation. J. Neurosci. 30, 14273-14283. doi: 10.1523/JNEUROSCI.1894-10.2010

Dreyer, J. K., Vander Weele, C. M., Lovic, V., and Aragona, B. J. (2016). Functionally distinct dopamine signals in nucleus accumbens core and shell in the freely moving rat. J. Neurosci. 36, 98-112. doi: 10.1523/JNEUROSCI.232615.2016

Drutel, G., Peitsaro, N., Karlstedt, K., Wieland, K., Smit, M. J., Timmerman, H., et al. (2001). Identification of rat $\mathrm{H}_{3}$ receptor isoforms with different brain expression and signaling properties. Mol. Pharmacol. 59, 1-8. doi: $10.1124 / \mathrm{mol} .59 .1 .1$

Durstewitz, D., Seamans, J. K., and Sejnowski, T. J. (2000). Neurocomputational models of working memory. Nat. Neurosci. 3, 1184-1191. doi: 10.1038/81460

Ericson, H., Watanabe, T., and Kühler, C. (1987). Morphological analysis of the tuberomammillary nucleus in the rat brain: delineation of subgroups with antibody against L-histidine decarboxylase as a marker. J. Comp. Neurol. 263, 1-24. doi: 10.1002/cne.902630102

Eschenko, O., Magri, C., Panzeri, S., and Sara, S. J. (2012). Noradrenergic neurons of the locus coeruleus are phase locked to cortical up-down states during sleep. Cereb. Cortex 22, 426-435. doi: 10.1093/cercor/bhr121

Eshel, N., Tian, J., Bukwich, M., and Uchida, N. (2016). Dopamine neurons share common response function for reward prediction error. Nat. Neurosci. 19, 479-486. doi: 10.1038/nn.4239

Feenstra, M. G. (2000). Dopamine and noradrenaline release in the prefrontal cortex in relation to unconditioned and conditioned stress and reward. Prog. Brain Res. 126, 133-163. doi: 10.1016/s0079-6123(00)26012-3

Feenstra, M. G., Botterblom, M. H., and Mastenbroek, S. (2000). Dopamine and noradrenaline efflux in the prefrontal cortex in the light and dark period: effects of novelty and handling and comparison to the nucleus accumbens. Neuroscience 100, 741-748. doi: 10.1016/s0306-4522(00) 00319-5

Feenstra, M. G., Vogel, M., Botterblom, M. H., Joosten, R. N., and de Bruin, J. P. (2001). Dopamine and noradrenaline efflux in the rat prefrontal cortex after classical aversive conditioning to an auditory cue. Eur. J. Neurosci. 13, 1051-1054. doi: 10.1046/j.0953-816x.2001.01471.x

Flik, G., Folgering, J. H., Cremers, T. I., Westerink, B. H., and Dremencov, E. (2015). Interaction between brain histamine and serotonin, norepinephrine, and dopamine systems: in vivo microdialysis and electrophysiology study. J. Mol. Neurosci. 56, 320-328. doi: 10.1007/s12031-015-0536-3

Floresco, S. B., West, A. R., Ash, B., Moore, H., and Grace, A. A. (2003). Afferent modulation of dopamine neuron firing differentially regulates tonic and phasic dopamine transmission. Nat. Neurosci. 6, 968-973. doi: 10.1038/ nn1103

Florin-Lechner, S. M., Druhan, J. P., Aston-Jones, G., and Valentino, R. J. (1996). Enhanced norepinephrine release in prefrontal cortex with burst stimulation of the locus coeruleus. Brain Res. 742, 89-97. doi: 10.1016/s0006-8993(96) 00967-5

Foote, S. L., Aston-Jones, G., and Bloom, F. E. (1980). Impulse activity of locus coeruleus neurons in awake rats and monkeys is a function of sensory stimulation and arousal. Proc. Natl. Acad. Sci. U S A 77, 3033-3037. doi: $10.1073 /$ pnas.77.5.3033

Foote, S. L., Bloom, F. E., and Aston-Jones, G. (1983). Nucleus locus ceruleus: new evidence of anatomical and physiological specificity. Physiol. Rev. 63, 844-914.

Freeman, A. S., and Bunney, B. S. (1987). Activity of A9 and A10 dopaminergic neurons in unrestrained rats: further characterization and effects of apomorphine and cholecystokinin. Brain Res. 405, 46-55. doi: 10.1016/00068993(87)90988-7

Fuxe, K., and Ungerstedt, U. (1968). Histochemical studies on the distribution of catecholamines and 5-hydroxytryptamine after intraventricular injections. Histochemie 13, 16-28. doi: 10.1007/bf00303872

Gaspar, P., Berger, B., Febvret, A., Vigny, A., and Henry, J. P. (1989). Catecholamine innervation of the human cerebral cortex as revealed by comparative immunohistochemistry of tyrosine hydroxylase and dopamine-beta-hydroxylase. J. Comp. Neurol. 279, 249-271. doi: 10.1002/cne. 902790208

Gaspar, P., Bloch, B., and Le Moine, C. (1995). D1 and D2 receptor gene expression in the rat frontal cortex: cellular localization in different classes of 
efferent neurons. Eur. J. Neurosci. 7, 1050-1063. doi: 10.1111/j.1460-9568.1995. tb01092.x

Gaspar, P., Duyckaerts, C., Alvarez, C., Javoy-Agid, F., and Berger, B. (1991). Alterations of dopaminergic and noradrenergic innervations in motor cortex in Parkinson's disease. Ann. Neurol. 30, 365-374. doi: 10.1002/ana. 410300308

Gee, S., Ellwood, I., Patel, T., Luongo, F., Deisseroth, K., and Sohal, V. S. (2012). Synaptic activity unmasks dopamine D2 receptor modulation of a specific class of layer V pyramidal neurons in prefrontal cortex. J. Neurosci. 32, 4959-4971. doi: 10.1523/JNEUROSCI.5835-11.2012

German, D. C., Manaye, K. F., White, C. L. III, Woodward, D. J., McIntire, D. D., Smith, W. K., et al. (1992). Disease-specific patterns of locus coeruleus cell loss. Ann. Neurol. 32, 667-676. doi: 10.1002/ana.410320510

Gesi, M., Soldani, P., Giorgi, F. S., Santinami, A., Bonaccorsi, I., and Fornai, F. (2000). The role of the locus coeruleus in the development of Parkinson's disease. Neurosci. Biobehav. Rev. 24, 655-668. doi: 10.1016/s01497634(00)00028-2

Godefroy, F., Bassant, M. H., Lamour, Y., and Weil-Fugazza, J. (1991). Effect of aging on dopamine metabolism in the rat cerebral cortex: a regional analysis. J. Neural Transm. Gen. Sect. 83, 13-24. doi: 10.1007/bf01244448

Goffinet, A. M., and De Volder, A. (1985). Autoradiographic analysis of adrenergic receptors in the mammalian brain. Acta Neurol. Belg. 85, 82-109.

Goldman-Rakic, P. S., Lidow, M. S., and Gallager, D. W. (1990). Overlap of dopaminergic, adrenergic, and serotoninergic receptors and complementarity of their subtypes in primate prefrontal cortex. J. Neurosci. 10, $2125-2138$.

Grace, A. A., and Bunney, B. S. (1984a). The control of firing pattern in nigral dopamine neurons: burst firing. J. Neurosci. 4, 2877-2890.

Grace, A. A., and Bunney, B. S. (1984b). The control of firing pattern in nigral dopamine neurons: single spike firing. J. Neurosci. 4, 2866-2876.

$\mathrm{Gu}$, Q. (2002). Neuromodulatory transmitter systems in the cortex and their role in cortical plasticity. Neuroscience 111, 815-835. doi: 10.1016/s03064522(02)00026-x

Guo, L., Xiong, H., Kim, J. I., Wu, Y. W., Lalchandani, R. R., Cui, Y., et al. (2015). Dynamic rewiring of neural circuits in the motor cortex in mouse models of Parkinson's disease. Nat. Neurosci. 18, 1299-1309. doi: 10.1038/nn.4082

Haas, H., and Panula, P. (2003). The role of histamine and the tuberomamillary nucleus in the nervous system. Nat. Rev. Neurosci. 4, 121-130. doi: $10.1038 / \mathrm{nrn} 1034$

Haas, H. L., Sergeeva, O. A., and Selbach, O. (2008). Histamine in the nervous system. Physiol. Rev. 88, 1183-1241. doi: 10.1152/physrev.00043.2007

Haas, H. L., and Wolf, P. (1977). Central actions of histamine: microelectrophoretic studies. Brain Res. 122, 269-279. doi: 10.1016/00068993(77)90294-3

Hajós, M., Allers, K. A., Jennings, K., Sharp, T., Charette, G., Sík, A., et al. (2007). Neurochemical identification of stereotypic burst-firing neurons in the rat dorsal raphe nucleus using juxtacellular labelling methods. Eur. J. Neurosci. 25, 119-126. doi: 10.1111/j.1460-9568.2006.05276.x

Hayashi, H., Takagi, H., Takeda, N., Kubota, Y., Tohyama, M., Watanabe, T., et al. (1984). Fine structure of histaminergic neurons in the caudal magnocellular nucleus of the rat as demonstrated by immunocytochemistry using histidine decarboxylase as a marker. J. Comp. Neurol. 229, 233-241. doi: 10.1002/cne. 902290208

Hedrick, T., and Waters, J. (2015). Acetylcholine excites neocortical pyramidal neurons via nicotinic receptors. J. Neurophysiol. 113, 2195-2209. doi: 10.1152/jn.00716.2014

Heron, C., Gould, T. J., and Bickford, P. (1996). Acquisition of a runway motor learning task is impaired by a beta adrenergic antagonist in F344 rats. Behav. Brain Res. 78, 235-241. doi: 10.1016/0166-4328(95)00252-9

Herwig, U., Bräuer, K., Connemann, B., Spitzer, M., and Schönfeldt-Lecuona, C. (2002). Intracortical excitability is modulated by a norepinephrine-reuptake inhibitor as measured with paired-pulse transcranial magnetic stimulation. Psychopharmacology (Berl) 164, 228-232. doi: 10.1007/s00213-002-1206-Z

Hira, R., Ohkubo, F., Ozawa, K., Isomura, Y., Kitamura, K., Kano, M., et al. (2013). Spatiotemporal dynamics of functional clusters of neurons in the mouse motor cortex during a voluntary movement. J. Neurosci. 33, 1377-1390. doi: 10.1523/jneurosci.2550-12.2013
Hobson, J. A., McCarley, R. W., and Wyzinski, P. W. (1975). Sleep cycle oscillation: reciprocal discharge by two brainstem neuronal groups. Science 189, 55-58. doi: $10.1126 /$ science. 1094539

Hosp, J. A., Molina-Luna, K., Hertler, B., Atiemo, C. O., and Luft, A. R. (2009). Dopaminergic modulation of motor maps in rat motor cortex: an in vivo study. Neuroscience 159, 692-700. doi: 10.1016/j.neuroscience.2008.12.056

Hosp, J. A., Nolan, H. E., and Luft, A. R. (2015). Topography and collateralization of dopaminergic projections to primary motor cortex in rats. Exp. Brain Res. 233, 1365-1375. doi: 10.1007/s00221-015-4211-2

Hosp, J. A., Pekanovic, A., Rioult-Pedotti, M. S., and Luft, A. R. (2011). Dopaminergic projections from midbrain to primary motor cortex mediate motor skill learning. J. Neurosci. 31, 2481-2487. doi: 10.1523/JNEUROSCI. 5411-10.2011

Hu, W., and Chen, Z. (2017). The roles of histamine and its receptor ligands in central nervous system disorders: an update. Pharmacol. Ther. 175, 116-132. doi: 10.1016/j.pharmthera.2017.02.039

Huda, K., Salunga, T. L., and Matsunami, K. (2001). Dopaminergic inhibition of excitatory inputs onto pyramidal tract neurons in cat motor cortex. Neurosci. Lett. 307, 175-178. doi: 10.1016/s0304-3940(01)01960-7

Huntley, G. W., Morrison, J. H., Prikhozhan, A., and Sealfon, S. C. (1992). Localization of multiple dopamine receptor subtype mRNAs in human and monkey motor cortex and striatum. Mol. Brain Res. 15, 181-188. doi: $10.1016 / 0169-328 \times(92) 90107-m$

Ilango, A., Shumake, J., Wetzel, W., Scheich, H., and Ohl, F. W. (2012). The role of dopamine in the context of aversive stimuli with particular reference to acoustically signaled avoidance learning. Front. Neurosci. 6:132. doi: 10.3389/fnins.2012.00132

Inoue, I., Yanai, K., Kitamura, D., Taniuchi, I., Kobayashi, T., Niimura, K., et al. (1996). Impaired locomotor activity and exploratory behavior in mice lacking histamine H1 receptors. Proc. Natl. Acad. Sci. U S A 93, 13316-13320. doi: 10.1073/pnas.93.23.13316

Inzunza, O., Serón-Ferré, M. J., Bravo, H., and Torrealba, F. (2000). Tuberomammillary nucleus activation anticipates feeding under a restricted schedule in rats. Neurosci. Lett. 293, 139-142. doi: 10.1016/s03043940(00)01516-0

Ishimatsu, M., and Williams, J. T. (1996). Synchronous activity in locus coeruleus results from dendritic interactions in pericoerulear regions. J. Neurosci. 16, 5196-5204.

Jaber, M., Robinson, S. W., Missale, C., and Caron, M. G. (1996). Dopamine receptors and brain function. Neuropharmacology 35, 1503-1519. doi: 10.1016/s0028-3908(96)00100-1

Jacobs, B. L., and Azmitia, E. C. (1992). Structure and function of the brain serotonin system. Physiol. Rev. 72, 165-229.

Jakab, R. L., and Goldman-Rakic, P. S. (1998). 5-Hydroxytryptamine2A serotonin receptors in the primate cerebral cortex: possible site of action of hallucinogenic and antipsychotic drugs in pyramidal cell apical dendrites. Proc. Natl. Acad. Sci. U S A 95, 735-740. doi: 10.1073/pnas.95.2.735

Janak, P. H., and Tye, K. M. (2015). From circuits to behaviour in the amygdala. Nature 517, 284-292. doi: 10.1038/nature14188

John, J., Wu, M. F., Boehmer, L. N., and Siegel, J. M. (2004). Cataplexyactive neurons in the hypothalamus: implications for the role of histamine in sleep and waking behavior. Neuron 42, 619-634. doi: 10.1016/s0896-6273(04) 00247-8

Jones, B. E. (2004). Activity, modulation and role of basal forebrain cholinergic neurons innervating the cerebral cortex. Prog. Brain Res. 145, 157-169. doi: 10.1016/s0079-6123(03)45011-5

Jones, B. E., Halaris, A. E., McIlhany, M., and Moore, R. Y. (1977). Ascending projections of the locus coeruleus in the rat. I. Axonal transport in central noradrenaline neurons. Brain Res. 127, 1-21. doi: 10.1016/00068993(77)90377-8

Jones, B. E., and Moore, R. Y. (1977). Ascending projections of the locus coeruleus in the rat. II. Autoradiographic study. Brain Res. 127, 25-53. doi: 10.1016/00068993(77)90378-x

Joo, K., Rhie, D.-J., and Jang, H.-J. (2015). Enhancement of GluN2B subunit-containing NMDA receptor underlies serotonergic regulation of long-term potentiation after critical period in the rat visual cortex. Korean J. Physiol. Pharmacol. 19, 523-531. doi: 10.4196/kjpp.2015.19. 6.523 
Joyce, J. N., Shane, A., Lexow, N., Winokur, A., Casanova, M. F., and Kleinman, J. E. (1993). Serotonin uptake sites and serotonin receptors are altered in the limbic system of schizophrenics. Neuropsychopharmacology 8, 315-336. doi: 10.1038/npp.1993.32

Kalisman, N., Silberberg, G., and Markram, H. (2005). The neocortical microcircuit as a tabula rasa. Proc. Natl. Acad. Sci. U S A 102, 880-885. doi: 10.1073/pnas.0407088102

Kirby, L. G., Pernar, L., Valentino, R. J., and Beck, S. G. (2003). Distinguishing characteristics of serotonin and non-serotonin-containing cells in the dorsal raphe nucleus: electrophysiological and immunohistochemical studies. Neuroscience 116, 669-683. doi: 10.1016/s0306-4522(02) 00584-5

Kiritani, T., Wickersham, I. R., Seung, H. S., and Shepherd, G. M. (2012). Hierarchical connectivity and connection-specific dynamics in the corticospinal-corticostriatal microcircuit in mouse motor cortex. J. Neurosci. 32, 4992-5001. doi: 10.1523/JNEUROSCI.4759-11.2012

Kish, S. J., Tong, J., Hornykiewicz, O., Rajput, A., Chang, L. J., Guttman, M., et al. (2008). Preferential loss of serotonin markers in caudate versus putamen in Parkinson's disease. Brain 131, 120-131. doi: 10.1093/brain/awm239

Kleim, J. A., Barbay, S., and Nudo, R. J. (1998). Functional reorganization of the rat motor cortex following motor skill learning. J. Neurophysiol. 80, 3321-3325.

Kleim, J. A., Hogg, T. M., VandenBerg, P. M., Cooper, N. R., Bruneau, R., and Remple, M. (2004). Cortical synaptogenesis and motor map reorganization occur during late, but not early, phase of motor skill learning. J. Neurosci. 24, 628-633. doi: 10.1523/JNEUROSCI.3440-03.2004

Kocsis, B., Varga, V., Dahan, L., and Sik, A. (2006). Serotonergic neuron diversity: identification of raphe neurons with discharges time-locked to the hippocampal theta rhythm. Proc. Natl. Acad. Sci. U S A 103, 1059-1064. doi: 10.1073/pnas.0508360103

Kosobud, A. E., Harris, G. C., and Chapin, J. K. (1994). Behavioral associations of neuronal activity in the ventral tegmental area of the rat. J. Neurosci. 14, 7117-7129.

Kosofsky, B. E., and Molliver, M. E. (1987). The serotoninergic innervation of cerebral cortex: different classes of axon terminals arise from dorsal and median raphe nuclei. Synapse 1, 153-168. doi: 10.1002/syn.890010204

Kroener, S., Chandler, L. J., Phillips, P. E., and Seamans, J. K. (2009). Dopamine modulates persistent synaptic activity and enhances the signal-to-noise ratio in the prefrontal cortex. PLoS One 4:e6507. doi: 10.1371/journal.pone. 0006507

Kunori, N., Kajiwara, R., and Takashima, I. (2014). Voltage-sensitive dye imaging of primary motor cortex activity produced by ventral tegmental area stimulation. J. Neurosci. 34, 8894-8903. doi: 10.1523/JNEUROSCI. 5286-13.2014

Kuo, H.-I., Paulus, W., Batsikadze, G., Jamil, A., Kuo, M.-F., and Nitsche, M. A. (2016). Chronic enhancement of serotonin facilitates excitatory transcranial direct current stimulation-induced neuroplasticity. Neuropsychopharmacology 41, 1223-1230. doi: 10.1038/npp.2015.270

Kuramoto, E., Furuta, T., Nakamura, K. C., Unzai, T., Hioki, H., and Kaneko, T. (2009). Two types of thalamocortical projections from the motor thalamic nuclei of the rat: a single neuron-tracing study using viral vectors. Cereb. Cortex 19, 2065-2077. doi: 10.1093/cercor/bhn231

Laing, M., and Bashir, Z. I. (2014). $\beta$-Adrenoceptors and synaptic plasticity in the perirhinal cortex. Neuroscience 273, 163-173. doi: 10.1016/j.neuroscience.2014. 04.070

Lei, W., Jiao, Y., Del Mar, N., and Reiner, A. (2004). Evidence for differential cortical input to direct pathway versus indirect pathway striatal projection neurons in rats. J. Neurosci. 24, 8289-8299. doi: 10.1523/JNEUROSCI. 1990-04.2004

Lev, D. L., and White, E. L. (1997). Organization of pyramidal cell apical dendrites and composition of dendritic clusters in the mouse: emphasis on primary motor cortex. Eur. J. Neurosci. 9, 280-290. doi: 10.1111/j.1460-9568.1997. tb01398.x

Lewis, D. A., Campbell, M. J., Foote, S. L., Goldstein, M., and Morrison, J. H. (1987). The distribution of tyrosine hydroxylase-immunoreactive fibers in primate neocortex is widespread but regionally specific. J. Neurosci. 7, 279-290.

Li, Y., Zhong, W., Wang, D., Feng, Q., Liu, Z., Zhou, J., et al. (2016). Serotonin neurons in the dorsal raphe nucleus encode reward signals. Nat. Commun. 7:10503. doi: $10.1038 /$ ncomms 10503
Lin, J. S. (2000). Brain structures and mechanisms involved in the control of cortical activation and wakefulness, with emphasis on the posterior hypothalamus and histaminergic neurons. Sleep Med. Rev. 4, 471-503. doi: 10.1053/smrv.2000.0116

Loane, C., Wu, K., Bain, P., Brooks, D. J., Piccini, P., and Politis, M. (2013). Serotonergic loss in motor circuitries correlates with severity of action-postural tremor in PD. Neurology 80, 1850-1855. doi: 10.1212/WNL. 0b013e318292a31d

López-Avila, A., Coffeen, U., Ortega-Legaspi, J. M., del Angel, R., and Pellicer, F. (2004). Dopamine and NMDA systems modulate long-term nociception in the rat anterior cingulate cortex. Pain 111, 136-143. doi: 10.1016/j.pain. 2004.06.010

Loubinoux, I., Boulanouar, K., Ranjeva, J. P., Carel, C., Berry, I., Rascol, O., et al. (1999). Cerebral functional magnetic resonance imaging activation modulated by a single dose of the monoamine neurotransmission enhancers fluoxetine and fenozolone during hand sensorimotor tasks. J. Cereb. Blood Flow Metab. 19, 1365-1375. doi: 10.1097/00004647-199912000-00010

Loubinoux, I., Pariente, J., Rascol, O., Celsis, P., and Chollet, F. (2002). Selective serotonin reuptake inhibitor paroxetine modulates motor behavior through practice. A double-blind, placebo-controlled, multi-dose study in healthy subjects. Neuropsychologia 40, 1815-1821. doi: 10.1016/s0028-3932(02) 00030-1

Loubinoux, I., Tombari, D., Pariente, J., Gerdelat-Mas, A., Franceries, X., Cassol, E., et al. (2005). Modulation of behavior and cortical motor activity in healthy subjects by a chronic administration of a serotonin enhancer. Neuroimage 27, 299-313. doi: 10.1016/j.neuroimage.2004.12.023

Lozeva, V., Valjakka, A., Lecklin, A., Olkkonen, H., Hippeläinen, M., Itkonen, M., et al. (2000). Effects of the histamine $\mathrm{H}_{1}$ receptor blocker, pyrilamine, on spontaneous locomotor activity of rats with long-term portacaval anastomosis. Hepatology 31, 336-344. doi: 10.1002/hep.510310212

Lucas-Meunier, E., Fossier, P., Baux, G., and Amar, M. (2003). Cholinergic modulation of the cortical neuronal network. Pflugers Arch. 446, 17-29. doi: 10.1007/s00424-002-0999-2

Lukhanina, E. P., Kolomiets, B. P., and Pilkevich, N. A. (2003). Effect of stimulation of beta-adrenergic receptors on neuronal activity in primary motor cortex of the rat. Neurosci. Lett. 340, 99-102. doi: 10.1016/s0304-3940(03) 00065-x

Mann, D. M., and Yates, P. O. (1983). Pathological basis for neurotransmitter changes in Parkinson's disease. Neuropathol. Appl. Neurobiol. 9, 3-19. doi: 10.1111/j.1365-2990.1983.tb00320.x

Manning, K. A., Wilson, J. R., and Uhlrich, D. J. (1996). Histamineimmunoreactive neurons and their innervation of visual regions in the cortex, tectum and thalamus in the primate Macaca mulatta. J. Comp. Neurol. 373, 271-282. doi: 10.1002/(sici)1096-9861(19960916)373:2<271::aid-cne9>3. 3.co; $2-\mathrm{w}$

Mansour, A., Meador-Woodruff, J. H., Bunzow, J. R., Civelli, O., Akil, H., and Watson, S. J. (1990). Localization of dopamine D2 receptor mRNA and D1 and D2 receptor binding in the rat brain and pituitary: an in situ hybridizationreceptor autoradiographic analysis. J. Neurosci. 10, 2587-2600.

Marien, M. R., Colpaert, F. C., and Rosenquist, A. C. (2004). Noradrenergic mechanisms in neurodegenerative diseases: a theory. Brain Res. Brain Res. Rev. 45, 38-78. doi: 10.1016/j.brainresrev.2004.02.002

Mastwal, S., Ye, Y., Ren, M., Jimenez, D. V., Martinowich, K., Gerfen, C. R., et al. (2014). Phasic dopamine neuron activity elicits unique mesofrontal plasticity in adolescence. J. Neurosci. 34, 9484-9496. doi: 10.1523/JNEUROSCI. 1114-14.2014

Matias, S., Lottem, E., Dugué, G. P., and Mainen, Z. F. (2017). Activity patterns of serotonin neurons underlying cognitive flexibility. Elife 6:e20552. doi: 10.7554/eLife.20552

McCall, J. G., Al-Hasani, R., Siuda, E. R., Hong, D. Y., Norris, A. J., Ford, C. P., et al. (2015). CRH engagement of the locus coeruleus noradrenergic system mediates stress-induced anxiety. Neuron 87, 605-620. doi: 10.1016/j.neuron.2015. 07.002

Meiser, J., Weindl, D., and Hiller, K. (2013). Complexity of dopamine metabolism. Cell Commun. Signal. 11:34. doi: 10.1186/1478-811X-11-34

Merickel, A., and Edwards, R. H. (1995). Transport of histamine by vesicular monoamine transporter-2. Neuropharmacology 34, 1543-1547. doi: 10.1016/0028-3908(95)00148-y 
Meunier, C. N. J., Amar, M., Lanfumey, L., Hamon, M., and Fossier, P. (2013). 5$\mathrm{HT}_{1 \mathrm{~A}}$ receptors direct the orientation of plasticity in layer 5 pyramidal neurons of the mouse prefrontal cortex. Neuropharmacology 71, 37-45. doi: 10.1016/j. neuropharm.2013.03.003

Meynard, M. M., Valdes, J. L., Recabarren, M., Serón-Ferré, M., and Torrealba, F. (2005). Specific activation of histaminergic neurons during daily feeding anticipatory behavior in rats. Behav. Brain Res. 158, 311-319. doi: 10.1016/j. bbr.2004.09.010

Mirenowicz, J., and Schultz, W. (1996). Preferential activation of midbrain dopamine neurons by appetitive rather than aversive stimuli. Nature 379, 449-451. doi: 10.1038/379449a0

Miyazaki, K. W., Miyazaki, K., Tanaka, K. F., Yamanaka, A., Takahashi, A., Tabuchi, S., et al. (2014). Optogenetic activation of dorsal raphe serotonin neurons enhances patience for future rewards. Curr. Biol. 24, 2033-2040. doi: 10.1016/j.cub.2014.07.041

Mochizuki, T., Yamatodani, A., Okakura, K., Horii, A., Inagaki, N., and Wada, H. (1992). Circadian rhythm of histamine release from the hypothalamus of freely moving rats. Physiol. Behav. 51, 391-394. doi: 10.1016/0031-9384(92)90157-w

Molina-Luna, K., Hertler, B., Buitrago, M. M., and Luft, A. R. (2008). Motor learning transiently changes cortical somatotopy. Neuroimage 40, 1748-1754. doi: 10.1016/j.neuroimage.2007.11.018

Molina-Luna, K., Pekanovic, A., Röhrich, S., Hertler, B., Schubring-Giese, M., Rioult-Pedotti, M. S., et al. (2009). Dopamine in motor cortex is necessary for skill learning and synaptic plasticity. PLoS One 4:e7082. doi: 10.1371/journal. pone. 0007082

Molyneaux, B. J., Arlotta, P., Menezes, J. R., and Macklis, J. D. (2007). Neuronal subtype specification in the cerebral cortex. Nat. Rev. Neurosci. 8, 427-437. doi: $10.1038 / \mathrm{nrn} 2151$

Monfils, M. H., Plautz, E. J., and Kleim, J. A. (2005). In search of the motor engram: motor map plasticity as a mechanism for encoding motor experience. Neuroscientist 11, 471-483. doi: 10.1177/1073858405278015

Monfils, M. H., and Teskey, G. C. (2004). Skilled-learning-induced potentiation in rat sensorimotor cortex: a transient form of behavioural long-term potentiation. Neuroscience 125, 329-336. doi: 10.1016/j.neuroscience. 2004.01.048

Morrison, J. H., and Foote, S. L. (1986). Noradrenergic and serotoninergic innervation of cortical, thalamic, and tectal visual structures in Old and New World monkeys. J. Comp. Neurol. 243, 117-138. doi: 10.1002/cne.902430110

Mouradian, R. D., Sessler, F. M., and Waterhouse, B. D. (1991). Noradrenergic potentiation of excitatory transmitter action in cerebrocortical slices: evidence for mediation by an $\alpha 1$ receptor-linked second messenger pathway. Brain Res. 546, 83-95. doi: 10.1016/0006-8993(91)91162-t

Neafsey, E. J., Bold, E. L., Haas, G., Hurley-Gius, K. M., Quirk, G., Sievert, C. F., et al. (1986). The organization of the rat motor cortex: a microstimulation mapping study. Brain Res. 396, 77-96. doi: 10.1016/s0006-8993(86)80191-3

Nitsche, M. A., Cohen, L. G., Wassermann, E. M., Priori, A., Lang, N., Antal, A., et al. (2008). Transcranial direct current stimulation: state of the art 2008. Brain Stimul. 1, 206-223. doi: 10.1016/j.brs.2008.06.004

Nitsche, M. A., Kuo, M.-F., Karrasch, R., Wächter, B., Liebetanz, D., and Paulus, W. (2009). Serotonin affects transcranial direct current-induced neuroplasticity in humans. Biol. Psychiatry 66, 503-508. doi: 10.1016/j. biopsych.2009.03.022

Nudo, R. J., Milliken, G. W., Jenkins, W. M., and Merzenich, M. M. (1996). Usedependent alterations of movement representations in primary motor cortex of adult squirrel monkeys. J. Neurosci. 16, 785-807.

O'Donnell, J. M. (1993). Effect of the beta-2 adrenergic agonist zinterol on norepinephrine turnover. Res. Commun. Chem. Pathol. Pharmacol. 80, 113-116.

Oswald, M. J., Tantirigama, M. L., Sonntag, I., Hughes, S. M., and Empson, R. M. (2013). Diversity of layer 5 projection neurons in the mouse motor cortex. Front. Cell. Neurosci. 7:174. doi: 10.3389/fncel.2013.00174

Palada, V., Terzic, J., Mazzulli, J., Bwala, G., Hagenah, J., Peterlin, B., et al. (2012). Histamine N-methyltransferase Thr105Ile polymorphism is associated with Parkinson's disease. Neurobiol. Aging 33, 836.e1-836.e3. doi: 10.1016/j. neurobiolaging.2011.06.015

Panula, P., Airaksinen, M. S., Pirvola, U., and Kotilainen, E. (1990). A histaminecontaining neuronal system in human brain. Neuroscience 34, 127-132. doi: 10.1016/0306-4522(90)90307-p
Panula, P., and Nuutinen, S. (2013). The histaminergic network in the brain: basic organization and role in disease. Nat. Rev. Neurosci. 14, 472-487. doi: 10.1038/nrn3526

Panula, P., Pirvola, U., Auvinen, S., and Airaksinen, M. S. (1989). Histamineimmunoreactive nerve fibers in the rat brain. Neuroscience 28, 585-610. doi: 10.1016/0306-4522(89)90007-9

Panula, P., Yang, H. Y., and Costa, E. (1984). Histamine-containing neurons in the rat hypothalamus. Proc. Natl. Acad. Sci. US A 81, 2572-2576. doi: 10.1073/pnas. 81.8.2572

Parmentier, R., Zhao, Y., Perier, M., Akaoka, H., Lintunen, M., Hou, Y., et al. (2016). Role of histamine H1-receptor on behavioral states and wake maintenance during deficiency of a brain activating system: a study using a knockout mouse model. Neuropharmacology 106, 20-34. doi: 10.1016/j. neuropharm.2015.12.014

Parr-Brownlie, L. C., and Hyland, B. I. (2005). Bradykinesia induced by dopamine D2 receptor blockade is associated with reduced motor cortex activity in the rat. J. Neurosci. 25, 5700-5709. doi: 10.1523/JNEUROSCI.052305.2005

Pazos, A., and Palacios, J. M. (1985). Quantitative autoradiographic mapping of serotonin receptors in the rat brain. I. Serotonin-1 receptors. Brain Res. 346, 205-230. doi: 10.1016/0006-8993(85)90857-1

Peters, A. J., Chen, S. X., and Komiyama, T. (2014). Emergence of reproducible spatiotemporal activity during motor learning. Nature 510, 263-267. doi: 10.1038/nature13235

Peyron, C., Tighe, D. K., van den Pol, A. N., de Lecea, L., Heller, H. C., Sutcliffe, J. G., et al. (1998). Neurons containing hypocretin (orexin) project to multiple neuronal systems. J. Neurosci. 18, 9996-10015.

Phillis, J. W., Tebecis, A. K., and York, D. H. (1968). Histamine and some antihistamines: their actions on cerebral cortical neurones. Br. J. Pharmacol. Chemother. 33, 426-440. doi: 10.1111/j.1476-5381.1968.tb00492.x

Pickel, V. M., Joh, T. H., and Reis, D. J. (1977). A serotonergic innervation of noradrenergic neurons in nucleus locus coeruleus: demonstration by immunocytochemical localization of the transmitter specific enzymes tyrosine and tryptophan hydroxylase. Brain Res. 131, 197-214. doi: 10.1016/00068993(77)90515-7

Plewnia, C., Hoppe, J., Cohen, L. G., and Gerloff, C. (2004). Improved motor skill acquisition after selective stimulation of central norepinephrine. Neurology 62, 2124-2126. doi: 10.1212/01.WNL.0000128041.92710.17

Politis, M., Wu, K., Loane, C., Kiferle, L., Molloy, S., Brooks, D. J., et al. (2010). Staging of serotonergic dysfunction in Parkinson's disease: an in vivo 11C-DASB PET study. Neurobiol. Dis. 40, 216-221. doi: 10.1016/j.nbd. 2010.05.028

Potjans, T. C., and Diesmann, M. (2014). The cell-type specific cortical microcircuit: relating structure and activity in a full-scale spiking network model. Cereb. Cortex 24, 785-806. doi: 10.1093/cercor/bhs358

Prast, H., Prast, M., and Philippu, A. (1994). H3 autoreceptors and muscarinic acetylcholine receptors modulate histamine release in the anterior hypothalamus of freely moving rats. Agents Actions 41, C64-C65. doi: 10.1007/bf02007769

Puig, M. V., Artigas, F., and Celada, P. (2005). Modulation of the activity of pyramidal neurons in rat prefrontal cortex by raphe stimulation in vivo: involvement of serotonin and GABA. Cereb. Cortex 15, 1-14. doi: 10.1093/cercor/bhh104

Puig, M. V., Watakabe, A., Ushimaru, M., Yamamori, T., and Kawaguchi, Y. (2010). Serotonin modulates fast-spiking interneuron and synchronous activity in the rat prefrontal cortex through $5-\mathrm{HT}_{1 \mathrm{~A}}$ and $5-\mathrm{HT}_{2 \mathrm{~A}}$ receptors. J. Neurosci. 30, 2211-2222. doi: 10.1523/JNEUROSCI.3335-09.2010

Raghanti, M. A., Stimpson, C. D., Marcinkiewicz, J. L., Erwin, J. M., Hof, P. R., and Sherwood, C. C. (2008). Cortical dopaminergic innervation among humans, chimpanzees, and macaque monkeys: a comparative study. Neuroscience 155, 203-220. doi: 10.1016/j.neuroscience.2008.05.008

Rainbow, T. C., Parsons, B., and Wolfe, B. B. (1984). Quantitative autoradiography of beta 1- and beta 2-adrenergic receptors in rat brain. Proc. Natl. Acad. Sci. U S A 81, 1585-1589. doi: 10.1073/pnas.81.5.1585

Rajkowski, J., Kubiak, P., and Aston-Jones, G. (1994). Locus coeruleus activity in monkey: phasic and tonic changes are associated with altered vigilance. Brain Res. Bull. 35, 607-616. doi: 10.1016/0361-9230(94) 90175-9 
Ramanathan, D. S., Conner, J. M., Anilkumar, A. A., and Tuszynski, M. H. (2015). Cholinergic systems are essential for late-stage maturation and refinement of motor cortical circuits. J. Neurophysiol. 113, 1585-1597. doi: 10.1152/jn. 00408.2014

Ramanathan, D., Tuszynski, M. H., and Conner, J. M. (2009). The basal forebrain cholinergic system is required specifically for behaviorally mediated cortical map plasticity. J. Neurosci. 29, 5992-6000. doi: 10.1523/JNEUROSCI. 0230-09.2009

Ramos, B. P., and Arnsten, A. F. (2007). Adrenergic pharmacology and cognition: focus on the prefrontal cortex. Pharmacol. Ther. 113, 523-536. doi: 10.1016/j. pharmthera.2006.11.006

Ranade, S. P., and Mainen, Z. F. (2009). Transient firing of dorsal raphe neurons encodes diverse and specific sensory, motor, and reward events. J. Neurophysiol. 102, 3026-3037. doi: 10.1152/jn.005 07.2009

Reiner, P. B., and McGeer, E. G. (1987). Electrophysiological properties of cortically projecting histamine neurons of the rat hypothalamus. Neurosci. Lett. 73, 43-47. doi: 10.1016/0304-3940(87)90028-0

Rinne, J. O., Anichtchik, O. V., Eriksson, K. S., Kaslin, J., Tuomisto, L., Kalimo, H., et al. (2002). Increased brain histamine levels in Parkinson's disease but not in multiple system atrophy. J. Neurochem. 81, 954-960. doi: 10.1046/j.1471-4159. 2002.00871.x

Rioult-Pedotti, M. S., Friedman, D., and Donoghue, J. P. (2000). Learninginduced LTP in neocortex. Science 290, 533-536. doi: 10.1126/science.290. 5491.533

Rioult-Pedotti, M. S., Friedman, D., Hess, G., and Donoghue, J. P. (1998). Strengthening of horizontal cortical connections following skill learning. Nat. Neurosci. 1, 230-234. doi: 10.1038/678

Rioult-Pedotti, M. S., Pekanovic, A., Atiemo, C. O., Marshall, J., and Luft, A. R. (2015). Dopamine promotes motor cortex plasticity and motor skill learning via PLC activation. PLoS One 10:e0124986. doi: 10.1371/journal.pone. 0124986

Rommelfanger, K. S., and Weinshenker, D. (2007). Norepinephrine: the redheaded stepchild of Parkinson's disease. Biochem. Pharmacol. 74, 177-190. doi: 10.1016/j.bcp.2007.01.036

Salgado, H., Köhr, G., and Treviño, M. (2012). Noradrenergic 'tone' determines dichotomous control of cortical spike-timing-dependent plasticity. Sci. Rep. 2:417. doi: 10.1038/srep00417

Santana, N., Bortolozzi, A., Serrats, J., Mengod, G., and Artigas, F. (2004). Expression of serotonin1A and serotonin2A receptors in pyramidal and GABAergic neurons of the rat prefrontal cortex. Cereb. Cortex 14, 1100-1109. doi: 10.1093/cercor/bhh070

Sastry, B. S., and Phillis, J. W. (1976a). Depression of rat cerebral cortical neurones by $\mathrm{H} 1$ and $\mathrm{H} 2$ histamine receptor agonists. Eur. J. Pharmacol. 38, 269-273. doi: 10.1016/0014-2999(76)90329-0

Sastry, B. S., and Phillis, J. W. (1976b). Evidence for an ascending inhibitory histaminergic pathway to the cerebral cortex. Can. J. Physiol. Pharmacol. 54, 782-786. doi: 10.1139/y76-109

Schiemann, J., Puggioni, P., Dacre, J., Pelko, M., Domanski, A., van Rossum, M. C., et al. (2015). Cellular mechanisms underlying behavioral state-dependent bidirectional modulation of motor cortex output. Cell Rep. 11, 1319-1330. doi: 10.1016/j.celrep.2015.04.042

Schultz, W. (1998). Predictive reward signal of dopamine neurons. J. Neurophysiol. $80,1-27$.

Schultz, W. (2010). Dopamine signals for reward value and risk: basic and recent data. Behav. Brain Funct. 6:24. doi: 10.1186/1744-90 81-6-24

Schwarz, L. A., and Luo, L. (2015). Organization of the locus coeruleusnorepinephrine system. Curr. Biol. 25, R1051-R1056. doi: 10.1016/j.cub.2015. 09.039

Schweimer, J., and Hauber, W. (2006). Dopamine D1 receptors in the anterior cingulate cortex regulate effort-based decision making. Learn. Mem. 13, 777-782. doi: 10.1101/lm.409306

Schweimer, J. V., and Ungless, M. A. (2010). Phasic responses in dorsal raphe serotonin neurons to noxious stimuli. Neuroscience 171, 1209-1215. doi: 10.1016/j.neuroscience.2010.09.058

Scullion, K., Boychuk, J. A., Yamakawa, G. R., Rodych, J. T. G., Nakanishi, S. T., Seto, A., et al. (2013). Serotonin 1A receptors alter expression of movement representations. J. Neurosci. 33, 4988-4999. doi: 10.1523/jneurosci. 4241-12.2013

Seamans, J. K., and Yang, C. R. (2004). The principal features and mechanisms of dopamine modulation in the prefrontal cortex. Prog. Neurobiol. 74, 1-58. doi: 10.1016/j.pneurobio.2004.05.006

Seol, G. H., Ziburkus, J., Huang, S., Song, L., Kim, I. T., Takamiya, K., et al. (2007). Neuromodulators control the polarity of spike-timing-dependent synaptic plasticity. Neuron 55, 919-929. doi: 10.1016/j.neuron.2007.08.013

Servan-Schreiber, D., Printz, H., and Cohen, J. D. (1990). A network model of catecholamine effects: gain, signal-to-noise ratio, and behavior. Science 249 , 892-895. doi: 10.1126/science.2392679

Shepherd, G. M. (2009). Intracortical cartography in an agranular area. Front. Neurosci. 3, 337-343. doi: 10.3389/neuro.01.030.2009

Shipley, M. T., Fu, L., Ennis, M., Liu, W. L., and Aston-Jones, G. (1996). Dendrites of locus coeruleus neurons extend preferentially into two pericoerulear zones. J. Comp. Neurol. 365, 56-68. doi: 10.1002/(sici)10969861(19960129)365:1<56::aid-cne5>3.0.co;2-i

Sjöström, P. J., Turrigiano, G. G., and Nelson, S. B. (2001). Rate, timing and cooperativity jointly determine cortical synaptic plasticity. Neuron 32 , 1149-1164. doi: 10.1016/s0896-6273(01)00542-6

Stefan, K., Kunesch, E., Cohen, L. G., Benecke, R., and Classen, J. (2000). Induction of plasticity in the human motor cortex by paired associative stimulation. Brain 123, 572-584. doi: 10.1093/brain/123.3.572

Steinbusch, H. W., Sauren, Y., Groenewegen, H., Watanabe, T., and Mulder, A. H. (1986). Histaminergic projections from the premammillary and posterior hypothalamic region to the caudate-putamen complex in the rat. Brain Res. 368, 389-393. doi: 10.1016/0006-8993(86)90588-3

Steriade, M., McCormick, D. A., and Sejnowski, T. J. (1993). Thalamocortical oscillations in the sleeping and aroused brain. Science 262, 679-685. doi: $10.1126 /$ science. 8235588

Stevens, D. R., Kuramasu, A., Eriksson, K. S., Selbach, O., and Haas, H. L. (2004). $\alpha$ 2 -adrenergic receptor-mediated presynaptic inhibition of GABAergic IPSPs in rat histaminergic neurons. Neuropharmacology 46, 1018-1022. doi: 10.1016/j. neuropharm.2004.01.004

Summers, R. J., and McMartin, L. R. (1993). Adrenoceptors and their second messenger systems. J. Neurochem. 60, 10-23. doi: 10.1111/j.1471-4159.1993. tb05817.x

Swanson, L. W. (1976). The locus coeruleus: a cytoarchitectonic, Golgi and immunohistochemical study in the albino rat. Brain Res. 110, 39-56. doi: 10.1016/0006-8993(76)90207-9

Swanson, L. W., and Hartman, B. K. (1975). The central adrenergic system. An immunofluorescence study of the location of cell bodies and their efferent connections in the rat utilizing dopamine-B-hydroxylase as a marker. J. Comp. Neurol. 163, 467-505. doi: 10.1002/cne.901630406

Takahashi, K., Lin, J. S., and Sakai, K. (2006). Neuronal activity of histaminergic tuberomammillary neurons during wake-sleep states in the mouse. J. Neurosci. 26, 10292-10298. doi: 10.1523/jneurosci.2341-06.2006

Tennant, K. A., Adkins, D. L., Donlan, N. A., Asay, A. L., Thomas, N., Kleim, J. A., et al. (2011). The organization of the forelimb representation of the C57BL/6 mouse motor cortex as defined by intracortical microstimulation and cytoarchitecture. Cereb. Cortex 21, 865-876. doi: 10.1093/cercor/ bhq159

Tian, M. K., Bailey, C. D., and Lambe, E. K. (2014). Cholinergic excitation in mouse primary vs. associative cortex: region-specific magnitude and receptor balance. Eur. J. Neurosci. 40, 2608-2618. doi: 10.1111/ejn.12622

Toyota, H., Dugovic, C., Koehl, M., Laposky, A. D., Weber, C., Ngo, K., et al. (2002). Behavioral characterization of mice lacking histamine $\mathrm{H}_{3}$ receptors. Mol. Pharmacol. 62, 389-397. doi: 10.1124/mol.62.2.389

Tseng, K. Y., Mallet, N., Toreson, K. L., Le Moine, C., Gonon, F., and O’Donnell, P. (2006). Excitatory response of prefrontal cortical fast-spiking interneurons to ventral tegmental area stimulation in vivo. Synapse 59, 412-417. doi: 10.1002/syn.20255

Tuomisto, L., Lozeva, V., Valjakka, A., and Lecklin, A. (2001). Modifying effects of histamine on circadian rhythms and neuronal excitability. Behav. Brain Res. 124, 129-135. doi: 10.1016/s0166-4328(01)00222-4

Valdés, J. L., Farías, P., Ocampo-Garcés, A., Cortés, N., Serón-Ferré, M., and Torrealba, F. (2005). Arousal and differential Fos expression in histaminergic neurons of the ascending arousal system during a feeding-related motivated 
behaviour. Eur. J. Neurosci. 21, 1931-1942. doi: 10.1111/j.1460-9568.2005. 04013.x

Valentino, R. J., and Foote, S. L. (1988). Corticotropin-releasing hormone increases tonic but not sensory-evoked activity of noradrenergic locus coeruleus neurons in unanesthetized rats. J. Neurosci. 8, 1016-1025.

Van Bockstaele, E. J., Colago, E. E., and Valentino, R. J. (1998). Amygdaloid corticotropin-releasing factor targets locus coeruleus dendrites: substrate for the co-ordination of emotional and cognitive limbs of the stress response. J. Neuroendocrinol. 10, 743-757. doi: 10.1046/j.1365-2826.1998. 00254.x

Van Bockstaele, E. J., Peoples, J., and Valentino, R. J. (1999). A.E. Bennett Research Award. Anatomic basis for differential regulation of the rostrolateral peri-locus coeruleus region by limbic afferents. Biol. Psychiatry 46, 1352-1363. doi: 10.1016/s0006-3223(99)00213-9

Vandermaelen, C. P., and Aghajanian, G. K. (1983). Electrophysiological and pharmacological characterization of serotonergic dorsal raphe neurons recorded extracellularly and intracellularly in rat brain slices. Brain Res. 289, 109-119. doi: 10.1016/0006-8993(83)90011-2

van Veldhuizen, M. J., Feenstra, M. G., and Boer, G. J. (1994). Regional differences in the in vivo regulation of the extracellular levels of noradrenaline and its metabolites in rat brain. Brain Res. 635, 238-248. doi: 10.1016/00068993(94)91445-1

van Veldhuizen, M. J., Feenstra, M. G., Boer, G. J., and Westerink, B. H. (1990). Microdialysis studies on cortical noradrenaline release: basic characteristics, significance of extracellular calcium and massive post-mortem increase. Neurosci. Lett. 119, 233-236. doi: 10.1016/0304-3940(90) 90841-v

Veasey, S. C., Fornal, C. A., Metzler, C. W., and Jacobs, B. L. (1997). Singleunit responses of serotonergic dorsal raphe neurons to specific motor challenges in freely moving cats. Neuroscience 79, 161-169. doi: 10.1016/s03064522(96)00673-2

Vertes, R. P. (1991). A PHA-L analysis of ascending projections of the dorsal raphe nucleus in the rat. J. Comp. Neurol. 313, 643-668. doi: 10.1002/cne. 903130409

Vitrac, C., Péron, S., Frappé, I., Fernagut, P. O., Jaber, M., Gaillard, A., et al. (2014). Dopamine control of pyramidal neuron activity in the primary motor cortex via D2 receptors. Front. Neural Circuits 8:13. doi: 10.3389/fncir.2014. 00013

Watanabe, T., Taguchi, Y., Hayashi, H., Tanaka, J., Shiosaka, S., Tohyama, M., et al. (1983). Evidence for the presence of a histaminergic neuron system in the rat brain: an immunohistochemical analysis. Neurosci. Lett. 39, 249-254. doi: 10.1016/0304-3940(83)90308-7

Watanabe, T., Taguchi, Y., Shiosaka, S., Tanaka, J., Kubota, H., Terano, Y., et al. (1984). Distribution of the histaminergic neuron system in the central nervous system of rats; a fluorescent immunohistochemical analysis with histidine decarboxylase as a marker. Brain Res. 295, 13-25. doi: 10.1016/00068993(84)90811-4

Waterhouse, B. D., Lin, C. S., Burne, R. A., and Woodward, D. J. (1983). The distribution of neocortical projection neurons in the locus coeruleus. J. Comp. Neurol. 217, 418-431. doi: 10.1002/cne.902170406

Waterhouse, B. D., Moises, H. C., and Woodward, D. J. (1980). Noradrenergic modulation of somatosensory cortical neuronal responses to iontophoretically applied putative neurotransmitters. Exp. Neurol. 69, 30-49. doi: 10.1016/00144886(80)90141-7

Waterhouse, B. D., Moises, H. C., Yeh, H. H., and Woodward, D. J. (1982). Norepinephrine enhancement of inhibitory synaptic mechanisms in cerebellum and cerebral cortex: mediation by beta adrenergic receptors. J. Pharmacol. Exp. Ther. 221, 495-506.

Waterhouse, B. D., Mouradian, R., Sessler, F. M., and Lin, R. C. (2000). Differential modulatory effects of norepinephrine on synaptically driven responses of layer V barrel field cortical neurons. Brain Res. 868, 39-47. doi: 10.1016/s00068993(00)02261-7

Waterhouse, B. D., Sessler, F. M., Cheng, J. T., Woodward, D. J., Azizi, S. A., and Moises, H. C. (1988). New evidence for a gating action of norepinephrine in central neuronal circuits of mammalian brain. Brain Res. Bull. 21, 425-432. doi: 10.1016/0361-9230(88)90154-2
Waterhouse, B. D., and Woodward, D. J. (1980). Interaction of norepinephrine with cerebrocortical activity evoked by stimulation of somatosensory afferent pathways in the rat. Exp. Neurol. 67, 11-34. doi: 10.1016/0014-4886(80) 90159-4

Weihe, E., and Eiden, L. E. (2000). Chemical neuroanatomy of the vesicular amine transporters. FASEB J. 14, 2435-2449. doi: 10.1096/fj.00-0202rev

Weiler, N., Wood, L., Yu, J., Solla, S. A., and Shepherd, G. M. (2008). Top-down laminar organization of the excitatory network in motor cortex. Nat. Neurosci. 11, 360-366. doi: 10.1038/nn2049

Whittington, M. A., Traub, R. D., and Jefferys, J. G. (1995). Synchronized oscillations in interneuron networks driven by metabotropic glutamate receptor activation. Nature 373, 612-615. doi: 10.1038/373612a0

Wilcox, B. J., and Seybold, V. S. (1982). Localization of neuronal histamine in rat brain. Neurosci. Lett. 29, 105-110. doi: 10.1016/0304-3940(82)90337-8

Williams, J. T., North, R. A., Shefner, S. A., Nishi, S., and Egan, T. M. (1984). Membrane properties of rat locus coeruleus neurones. Neuroscience 13, 137-156. doi: 10.1016/0306-4522(84)90265-3

Wilson, M. A., and Molliver, M. E. (1991). The organization of serotonergic projections to cerebral cortex in primates: regional distribution of axon terminals. Neuroscience 44, 537-553. doi: 10.1016/0306-4522(91)90076-z

Wouterlood, F. G., and Gaykema, R. P. (1988). Innervation of histaminergic neurons in the posterior hypothalamic region by medial preoptic neurons. Anterograde tracing with Phaseolus vulgaris leucoagglutinin combined with immunocytochemistry of histidine decarboxylase in the rat. Brain Res. 455, 170-176. doi: 10.1016/0006-8993(88)90129-1

Wouterlood, F. G., Gaykema, R. P., Steinbusch, H. W., Watanabe, T., and Wada, H. (1988). The connections between the septum-diagonal band complex and histaminergic neurons in the posterior hypothalamus of the rat. Anterograde tracing with Phaseolus vulgaris-leucoagglutinin combined with immunocytochemistry of histidine decarboxylase. Neuroscience 26, 827-845. doi: 10.1016/0306-4522(88)90103-0

Wouterlood, F. G., Sauren, Y. M., and Steinbusch, H. W. (1986). Histaminergic neurons in the rat brain: correlative immunocytochemistry, Golgi impregnation, and electron microscopy. J. Comp. Neurol. 252, 227-244. doi: $10.1002 /$ cne. 902520207

Wouterlood, F. G., Steinbusch, H. W., Luiten, P. G., and Bol, J. G. (1987). Projection from the prefrontal cortex to histaminergic cell groups in the posterior hypothalamic region of the rat. Anterograde tracing with Phaseolus vulgaris leucoagglutinin combined with immunocytochemistry of histidine decarboxylase. Brain Res. 406, 330-336. doi: 10.1016/0006-8993(87) 90802-x

Yamawaki, N., Borges, K., Suter, B. A., Harris, K. D., and Shepherd, G. M. (2014). A genuine layer 4 in motor cortex with prototypical synaptic circuit connectivity. Elife 3:e05422. doi: 10.7554/elife.05422

Zhang, Z. W., and Deschênes, M. (1997). Intracortical axonal projections of lamina VI cells of the primary somatosensory cortex in the rat: a single-cell labeling study. J. Neurosci. 17, 6365-6379.

Zhang, Z. W., and Deschênes, M. (1998). Projections to layer VI of the posteromedial barrel field in the rat: a reappraisal of the role of corticothalamic pathways. Cereb. Cortex 8, 428-436. doi: 10.1093/cercor/ 8.5.428

Zhou, H.-C., Sun, Y.-Y., Cai, W., He, X.-T., Yi, F., Li, B.-M., et al. (2013). Activation of $\beta 2$-adrenoceptor enhances synaptic potentiation and behavioral memory via cAMP-PKA signaling in the medial prefrontal cortex of rats. Learn. Mem. 20, 274-284. doi: 10.1101/lm.030411.113

Conflict of Interest Statement: The authors declare that the research was conducted in the absence of any commercial or financial relationships that could be construed as a potential conflict of interest.

Copyright (c) 2017 Vitrac and Benoit-Marand. This is an open-access article distributed under the terms of the Creative Commons Attribution License (CC BY). The use, distribution or reproduction in other forums is permitted, provided the original author(s) or licensor are credited and that the original publication in this journal is cited, in accordance with accepted academic practice. No use, distribution or reproduction is permitted which does not comply with these terms. 